\title{
Orexin-A Intensifies Mouse Pupillary Light Response by Modulating Intrinsically Photosensitive Retinal Ganglion Cells
}

\author{
Wei Zhou, Li-Qin Wang, Yu-Qi Shao, Xu Han, Chen-Xi Yu, Fei Yuan, Xin Wang, Shi-Jun Weng, \\ - Yong-Mei Zhong, and Xiong-Li Yang \\ Department of Ophthalmology and Department of Neurology, State Key Laboratory of Medical Neurobiology and MOE Frontiers Center for Brain \\ Science, Institutes of Brain Science, Zhongshan Hospital, Fudan University, Shanghai, 200032, China
}

We show for the first time that the neuropeptide orexin modulates pupillary light response, a non-image-forming visual function, in mice of either sex. Intravitreal injection of the orexin receptor (OXR) antagonist TCS1102 and orexin-A reduced and enhanced pupillary constriction in response to light, respectively. Orexin-A activated $\mathrm{OX}_{1} \mathrm{Rs}$ on $\mathrm{M} 2$-type intrinsically photosensitive retinal ganglion cells (M2 cells), and caused membrane depolarization of these cells by modulating inward rectifier potassium channels and nonselective cation channels, thus resulting in an increase in intrinsic excitability. The increased intrinsic excitability could account for the orexin-A-evoked increase in spontaneous discharges and light-induced spiking rates of M2 cells, leading to an intensification of pupillary constriction. Orexin-A did not alter the light response of M1 cells, which could be because of no or weak expression of $\mathrm{OX}_{1} \mathrm{Rs}$ on them, as revealed by RNAscope in situ hybridization. In sum, orexin-A is likely to decrease the pupil size of mice by influencing M2 cells, thereby improving visual performance in awake mice via enhancing the focal depth of the eye's refractive system.

Key words: intrinsic excitability; intrinsically photosensitive retinal ganglion cell; light response; melanopsin; orexin; pupillary light response

\section{Significance Statement}

This study reveals the role of the neuropeptide orexin in mouse pupillary light response, a non-image-forming visual function. Intravitreal orexin-A administration intensifies light-induced pupillary constriction via increasing the excitability of M2 intrinsically photosensitive retinal ganglion cells by activating the orexin receptor subtype $\mathrm{OX}_{1} \mathrm{R}$. Modulation of inward rectifier potassium channels and nonselective cation channels were both involved in the ionic mechanisms underlying such intensification. Orexin could improve visual performance in awake mice by reducing the pupil size and thereby enhancing the focal depth of the eye's refractive system.

\section{Introduction}

Intrinsically photosensitive retinal ganglion cells (ipRGCs), containing the photopigment melanopsin, represent the third class

\footnotetext{
Received Jan. 26, 2020; revised Jan. 16, 2021; accepted Jan. 22, 2021.

Author contributions: W.Z., L.-Q.W., Y.-Q.S., X.H., and C.-X.Y. performed research; W.Z., F.Y., X.W., S.-J.W., Y.-M.Z., and X.-L.Y. analyzed data; W.Z. wrote the first draft of the paper; W.Z., S.-J.W., Y.-M.Z., and X.-L.Y. wrote the paper; W.Z., S.-J.W., Y.-M.Z., and X.-L.Y. designed research.

This work was supported by National Natural Science Foundation of China 81790640, 31872766, $32070989,31571075,82070993,31571072,81430007$, and 81470661; Ministry of Science and Technology of China 2011CB504602 and 2015AA020512; Shanghai Municipal Science and Technology Major Project 2018SHZDZX01; and ZJLab and Sanming Project of Medicine in Shenzhen SZSM202011015. We thank Dr. Tian Xue for kindly providing the genetic mice.

The authors declare no competing financial interests.

Correspondence should be addressed to Xiong-Li Yang at xlyang@fudan.edu.cn or Yong-Mei Zhong at ymzhong@fudan.edu.cn or Shi-Jun Weng at sjweng@fudan.edu.cn.

https://doi.org/10.1523/JNEUROSCI.0217-20.2021

Copyright $\odot 2021$ the authors
}

of photoreceptors in the retina in addition to the two classical types, rods and cones (Berson et al., 2002; Hattar et al., 2002). Under physiological conditions, the responses of ipRGCs to light are driven not only by signals from photoreceptors through ON bipolar cells (extrinsic light response), but also by melanopsin (intrinsic light response) (Zhao et al., 2014). ipRGCs are commonly classified into six subtypes (M1-M6), based on their distinct dendritic branching patterns, physiological responses, and central projections (Do, 2019; Aranda and Schmidt, 2020; Sondereker et al., 2020). They are known to project to a variety of subcortical nuclei, including the hypothalamic suprachiasmatic nucleus (SCN) and the olivary pretectal nucleus (OPN), which are primarily responsible for circadian photoentrainment and the pupillary light response (PLR), respectively (Baver et al., 2008). While the PLR is not directly involved in image-forming (pattern) visual functions, it plays an important role in nonimage-forming visual functions and is principally mediated by 
ipRGCs at least in rodents, as evidenced by its complete elimination in ipRGC-ablated mice (Guler et al., 2008; Hatori et al., 2008).

The neuropeptides orexin- $\mathrm{A}$ and orexin- $\mathrm{B}$ (also known as hypocretin- 1 and -2 , respectively) are derived from a common precursor polypeptide (prepro-orexin) and originate from the lateral hypothalamic neurons, which project to the whole brain (de Lecea et al., 1998; Sakurai et al., 1998). These peptides regulate the sleep/wake cycle, feeding behavior, metabolism, and reproduction by activating two orexin receptors (OXRs), $\mathrm{OX}_{1} \mathrm{R}$ and $\mathrm{OX}_{2} \mathrm{R}$ (de Lecea and Sutcliffe, 2005; Matsuki and Sakurai, 2008; Sakurai et al., 2010). In the rat retina, orexins are expressed by almost all types of neurons except photoreceptors, whereas $\mathrm{OX}_{1} \mathrm{Rs}$ are expressed on dopaminergic amacrine cells (ACs) and most retinal ganglion cells (GCs), including ipRGCs (Liu et al., 2011). It has been demonstrated that orexins modify imageforming visual functions by affecting neuronal activities in both the inner and outer retina (Zheng et al., 2015; Qiao et al., 2017; G. Zhang et al., 2018). However, there are no data available concerning whether and how orexins could modulate non-imageforming visual functions. In the present work, we demonstrate that orexin-A significantly intensifies the PLR in mice by activating $\mathrm{OX}_{1} \mathrm{Rs}$ in $\mathrm{M} 2$ cells. We further show that this effect of orexin-A comes into play because of an increased intrinsic excitability of M2 cells following the direct activation of $\mathrm{OX}_{1} \mathrm{Rs}$ on these cells. This is the first report showing that orexins could modulate non-image-forming vision.

\section{Materials and Methods}

Animals. All animal experiments were performed in accordance with the standards of the Animal Care and Use Committee of Shanghai Medical College, Fudan University, and the National Institutes of Health's Guide for the care and use of laboratory animals. C57BL/6, Opn4-tdTomato, Opn $4^{-1-}$, and $r d / r d c l$ mice were used in the present work. In Opn4-tdTomato mice, M1-M3 ipRGCs, which are genetically labeled by the red fluorescent protein tdTomato (Do et al., 2009), could be reliably identified under the microscope used in this work. The Opn $4^{-1-}$ mouse (Xue et al., 2011), with melanopsin knocked out and ipRGCs labeled by tdTomato, was created by mating the melanopsin-deficient Opn $4^{\text {LacZ/LacZ }}$ line (Hattar et al., 2002) with the Opn4-tdTomato line. The $r d / r d c l$ mouse was generated by crossing $r d 1$ with the Cone$D T A$ mouse, in which rods and cones progressively degenerate and are virtually absent at $\sim 80 \mathrm{~d}$ postnatally (Lucas et al., 1999). Both male and female mice were used in the experiments. C57BL/6, Opn4-tdTomato, and $O p n 4^{-1-}$ mice were 2-4 months old, whereas $r d / r d ~ c l$ mice were at least $80 \mathrm{~d}$ old to ensure complete loss of rod/cone photoreceptors. They were housed under a 12:12 h light-dark cycle, with the light turned on at 8:00 A.M

Electrophysiology. Before each experiment, each animal was darkadapted for at least $2 \mathrm{~h}$. All animals were overdosed with $25 \%$ urethane $(0.2 \mathrm{ml} / 100 \mathrm{~g})$ under dim red light. Both eyes were harvested and placed in Ames' medium (MilliporeSigma) equilibrated with carbogen. The retina was isolated from the pigment epithelium and placed in a recording chamber mounted on the stage of an upright, fixed-stage fluorescence microscope (BX51WI; Olympus). The preparation was continuously perfused with oxygenated Ames' medium $\left(30^{\circ} \mathrm{C}-32^{\circ} \mathrm{C}\right)$ at a rate of $\sim 3 \mathrm{ml} / \mathrm{min}$ and kept in darkness for $\sim 1 \mathrm{~h}$ before electrophysiological recordings. TdTomato-labeled ipRGCs were visualized by epifluorescence with $530-550 \mathrm{~nm}$ light excitation [14.45 log photons $/ \mathrm{cm}^{2} / \mathrm{s}$ measured at $540 \mathrm{~nm}$ with a model 350 optometer (UDT Instruments)] using a rhodamine filter cube (U-MWIG3; Olympus) through a $60 \times$ water immersion objective (numerical aperture $=0.9$ ). After brief exposure to fluorescent excitation for $3-10$ s to locate ipRGCs, the retina was maintained in darkness for $10 \mathrm{~min}$ before recording. Glass micropipettes with tip resistance of 5-7 $\mathrm{M} \Omega$ were pulled from thin-walled borosilicate tubes
(BF 150-110-10; Sutter Instrument) using a P-97 puller (Sutter). Cellattached recordings were made using glass electrodes filled with a solution of $150 \mathrm{~mm} \mathrm{NaCl}$ and $10 \mathrm{~mm}$ HEPES in voltage-clamp configuration with a holding potential of $0 \mathrm{mV}$ and seal resistance $>500 \mathrm{M} \Omega$. For all current-clamp recordings, a $\mathrm{K}^{+}$-based intracellular solution was used, containing the following (in $\mathrm{mm}$ ): $120 \mathrm{~K}$-gluconate, $5 \mathrm{NaCl}$, $4 \mathrm{KCl}, 10$ HEPES, 2 EGTA, $4 \mathrm{Mg}$-ATP, $0.3 \mathrm{Na}$-GTP, 7 Tris-phosphocreatine, and $0.1 \%$ Lucifer yellow (LY); the $\mathrm{pH}$ was adjusted to 7.3 with $\mathrm{KOH}$. For all voltage-clamp recordings, we used a $\mathrm{Cs}^{+}$-based intracellular solution containing the following (in mM): $120 \mathrm{CsMeSO}_{4}$, $5 \mathrm{NaCl}, 4$ TEA-Cl, 10 HEPES, 2 EGTA, $4 \mathrm{Mg}$-ATP, 0.3 Na-GTP, 7 Tris-phosphocreatine, and $0.1 \% \mathrm{LY}$; the $\mathrm{pH}$ was adjusted to 7.3 with $\mathrm{CsOH}$. Fast capacitance was fully canceled, and cell capacitance was partially canceled using the amplifier. The holding potential was $-73 \mathrm{mV}$, which was near the reversal potential of $\mathrm{Cl}^{-}$for voltage clamping. The holding current was $0 \mathrm{pA}$ for current clamping. Data were obtained using an Axon 700B amplifier (Molecular Devices) and a HEKA EPC10 amplifier (HEKA Elektronik). Signals were low-pass filtered at $2 \mathrm{kHz}$ and sampled at $10 \mathrm{kHz}$. Series resistance was typically between 20 and $40 \mathrm{M} \Omega$ and was compensated by $\sim 70 \%$. Effects of all the pharmacological manipulations reported in this work were reversible. Data collected from cells that failed to show an evident recovery from drug treatments (at the time when the preparations had been washed out for at least $10 \mathrm{~min}$ ) were discarded and not included for further analysis.

Light stimulation. Full-field blue light, which was emitted from an LED illuminator (X-Cite 110 LED; Excelitas Technology) and bandpass filtered at $475 \pm 15 \mathrm{~nm}$ with a fluorescent filter cube (U-M650; Olympus) incorporated into the microscope light path, was used to evoke light responses from ipRGCs through the $60 \times$ objective. Light intensity was adjusted by neutral density filters in a 10 position $25 \mathrm{~mm}$ electronic filter wheel (LB-10; Sutter) coupled to the microscope. To obtain the irradiance-response (I-R) relations in Figure 2D2, stimuli were applied to two groups of cells (DMSO and TCS1102) in a series, which was monotonically ascending in intensity (each intensity applied only once), ranging from 11.52 to $15.89 \log$ photons $/ \mathrm{cm}^{2} / \mathrm{s}$, with interstimulus intervals varied with the light intensity, being shortest for the dimmest stimuli ( $3 \mathrm{~min}$ ) and longest for the highest intensities ( $7 \mathrm{~min}$ ), so as to minimize the effects of light adaption while completing the experiment as quickly as practical, avoiding response rundown. In other experiments, cells were repeatedly stimulated at a single intensity, with interstimulus intervals fixed to be $7 \mathrm{~min}$ (for intrinsic light response, $13.84 \log$ photons $/ \mathrm{cm}^{2} / \mathrm{s}$ ) or $3 \mathrm{~min}$ (for extrinsic light response, $9.61 \mathrm{log}$ photons $/ \mathrm{cm}^{2} / \mathrm{s}$ ), and data collection (control, drug treatment, and washout) was not initiated until the first 1 or 2 stimulations had been applied. In such experimental paradigms, a control experiment found that the response amplitude could be very stable $(<8 \%$ fluctuation of the response amplitudes) for at least $40 \mathrm{~min}$ in agonist-/antagonist-free environments.

Identification of ipRGC subtypes. Immediately after whole-cell recording, the cell was visualized via the fluorescence of LY, which was included in the internal solution, and identified morphologically. In cellattached patch experiments, when the recordings were finished, an electrode filled with LY-containing internal solution was sealed with the cell and the cell membrane was ruptured to allow LY to enter. Cell identity was confirmed offline by immunostaining of LY to enhance fluorescent signals, with ChAT-immunoreactive bands used as retinal laminar references. Cells with sparser dendrites exclusively stratifying in the OFF sublamina of the inner plexiform layer (IPL) were categorized as M1 cells. $\mathrm{ON}$-stratified cells with wider dendritic fields and relatively denser dendrites, somewhat below the ON ChAT-labeled band, were categorized as M2 cells.

Immunohistochemical staining of retinal whole mounts. The retinas were fixed with $4 \%$ PFA in $0.1 \mathrm{M}$ fresh $\mathrm{PB}$ for $30 \mathrm{~min}$, rinsed with $0.01 \mathrm{M}$ PBS, $\mathrm{pH} 7.4$, and blocked for $2 \mathrm{~h}$ in $0.1 \mathrm{M}$ PBS, $\mathrm{pH} 7.4$, containing $6 \%$ donkey serum plus $1 \%$ Triton $\mathrm{X}-100$. The cells were incubated with the primary antibodies for $3 \mathrm{~d}$ at $4{ }^{\circ} \mathrm{C}$ in $0.1 \mathrm{M} \mathrm{PBS}$ containing $3 \%$ donkey serum, $1 \% \mathrm{BSA}$, and $1 \%$ Triton $\mathrm{X}-100$. The binding sites of the primary antibodies were revealed by incubation with the fluorescent secondary 
antibodies for $2 \mathrm{~h}$ at room temperature. A rabbit polyclonal antibody against LY (1:1000, A5750; Invitrogen), a goat polyclonal antibody against ChAT (1:1000, AB144P; Millipore), and a mouse monoclonal antibody against SMI32 (1:1000, SMI32R, Covance) were used to enhance LY fluorescence, to label cholinergic ACs, and to label M4 ipRGCs, respectively. The secondary antibodies were Alexa-488-conjugated donkey anti-rabbit IgG for LY, Alexa-555-conjugated donkey antigoat IgG for ChAT, and Alexa-647-conjugated donkey anti-mouse IgG for SMI32 (1:200; all from Invitrogen).

Determination of membrane properties. To measure input resistance $\left(\mathrm{R}_{\mathrm{m}}\right)$, under current-clamp mode, ipRGCs were maintained at $-83 \pm$ $5 \mathrm{mV}$ with an appropriate current to eliminate spontaneous discharge. The peak voltage change $(\Delta \mathrm{V})$ induced by injection of a $1 \mathrm{~s}$ hyperpolarizing current with an amplitude of $35 \mathrm{pA}(\Delta \mathrm{I})$ was measured. $\mathrm{R}_{\mathrm{m}}$ was obtained using Ohm's law: $\mathrm{R}_{\mathrm{m}}=\Delta \mathrm{V} / \Delta \mathrm{I}$. To measure the action potential threshold, $1 \mathrm{~s}$ depolarizing current, increasing in $10 \mathrm{pA}$ increments, were applied to each ipRGC. The action potential threshold was defined as the membrane potential at which the upstroke of the first spike was induced by the lowest-amplitude current.

Intravitreal microinjection and pupillometry. All mice subjected to intravitreal injection were dark-adapted for at least $2 \mathrm{~h}$ and anesthetized by isoflurane using a small animal anesthesia instrument (RWD). Under dim red light, $1 \mu \mathrm{l}$ solution containing the dual OXR antagonist TCS1102 or orexin-A was injected intravitreally into the left eyes of the mice using a Nanoject II microinjector (Drummond Scientific); an equal volume of vehicle DMSO solution for TCS1102 and saline for orexin-A was injected into the left eyes in another group as a control. The final vitreal concentration was calculated based on a mouse vitreal volume of $5.3 \mu \mathrm{l}$ (Remtulla and Hallett, 1985). A 15 min recovery period was allowed before PLR measurements. All PLR recordings were conducted during the light period (ZT6-ZT12). Under dim red illumination, the mouse was placed in a head-and-body restrainer device with a metal bar (implanted into the skull $2 \mathrm{~d}$ before the recording) fixed to the device, and PLRs were recorded using a pupilometer (A2000; Neuroptics) in combination with Bandicam software (Bandicam). The right eye of each mouse was oriented in the direction of the infrared video camera, with the left eye subjected to the light stimulus. Pupil areas were measured both in the dark and during application of the light stimulus (20 s), and the interval between two consecutive light stimuli was $5 \mathrm{~min}$. The percentage of pupil constriction was calculated as $\left(1-A_{\min } / A_{O}\right) \times 100 \%$, where $A_{\min }$ is the minimum pupil area during light exposure and $A_{O}$ is the pupil area immediately before light exposure. In the melanopsinmediated PLR experiments, light of increasing intensity $(11.09,11.59$, $12.09,12.59,13.09,13.59,14.09,14.59$, and $15.09 \log$ photons $\left./ \mathrm{cm}^{2} / \mathrm{s}\right)$ was presented. In the rod/cone-mediated PLR experiments, the light intensities were 8.09, 9.09, 10.09, 11.09, 11.59, and $12.09 \log$ photons $/ \mathrm{cm}^{2} / \mathrm{s}$.

Multiplexing of RNAscope in situ hybridization (ISH) with immunostaining. Animals were deeply anesthetized with $25 \%$ urethane. Isolated eye cups were immersion-fixed in fresh $4 \%$ PFA in $0.1 \mathrm{M} \mathrm{PB}, \mathrm{pH} 7.4$, for $1 \mathrm{~h}$ and then cryoprotected at $4^{\circ} \mathrm{C}$ in successive solutions of $0.1 \mathrm{M}$ PBS containing $10 \%(\mathrm{w} / \mathrm{v}), 20 \%, 30 \%$ of sucrose. After that, the eye cups were embedded and stored at $-80^{\circ} \mathrm{C}$ in optimal cutting temperature medium (Salura Finetek) until being sectioned at $14 \mu \mathrm{m}$ using a CM1950 cryostat microtome (Leica Microsystems). The sections were mounted on chrome alum gelatin-coated slides (Shitai). After rinsing with $0.01 \mathrm{M}$ PBS, they were pretreated with blocking solution (6\% donkey serum, $0.2 \%$ Triton X-100 in 0.1 м PBS) for $2 \mathrm{~h}$ at room temperature. For immunofluorescence labeling, the following specific antibodies were used as primary antibodies: rabbit anti-melanopsin (UF-008, 1:10,000; Advanced Targeting Systems); rabbit anti-melanopsin (PA1-780, 1:1000; Invitrogen); and goat anti-mcherry (ab125096, 1:500; Abcam). The sections were incubated with primary antibodies in a buffer solution (3\% donkey serum, $1 \%$ bovine serum, and $0.2 \%$ Triton X-100 in $0.1 \mathrm{M}$ PBS) for $3 \mathrm{~d}$ at $4^{\circ} \mathrm{C}$ and washed $(3 \times 15 \mathrm{~min})$ in $0.1 \mathrm{~m}$ PBS. These sections were then incubated with secondary antibodies for $2 \mathrm{~h}$ at room temperature in the dark. After finishing immunofluorescent staining, a customized probe from Advanced Cell Diagnostics was used to detect $\mathrm{OX}_{1} \mathrm{R}$ mRNA (466631) following the manufacturer's instruction, except that the protease digestion time was reduced from 30 to $15 \mathrm{~min}$. Last, the sections were coverslipped with Vectashield mounting medium (Vector Laboratories).
Image acquisition. Images were obtained using a fluorescent confocal microscope (Fluoview 1000, Olympus) with a $60 \times$ oil immersion objective lens. To avoid any possible reconstruction stacking artifact, images were acquired separately from each laser channel on single-layer optical sections. Photoshop CC 2019 (Adobe) was used to adjust image brightness and contrast globally.

Chemicals. L-AP4, DNQX, D-AP5, orexin-A, TCS1102, TCS OX229, SB334867, carbenoxolone disodium, and Tertiapin-Q were purchased from Tocris Bioscience. All other chemicals were obtained from MilliporeSigma. TCS1102 and SB334867 were initially dissolved in DMSO for stock, while all other drugs were directly dissolved in ion-free water to make aliquots. All aliquots were stored at $-20^{\circ} \mathrm{C}$ and freshly diluted to working concentrations with saline (for PLR recording) or Ames' medium (for patch-clamp recording) on the day of the experiment.

Experimental design and statistical analysis. Any results reported in this study are highly reproducible, being replicated in at least 3 (typically $n>6$ ) animals or cells. Control data were collected from animals/cells treated with drug vehicles. Data were analyzed using Clampfit (Molecular Devices), SigmaPlot 10.0 (Systat Software), and CorelDRAW X7 (Corel). Data are presented as mean \pm SEM. For statistical analysis, KolmogorovSmirnov test was first used to check the normality of the data distribution, which determined whether parametric or nonparametric tests were used subsequently. Unless otherwise specified, $p$ values represented the results of paired Student's $t$ test. In all cases, $p<0.05$ was considered indicative of statistical significance.

\section{Results}

\section{Modulation by orexins of PLR in mice}

As orexin- $\mathrm{A}$ and $-\mathrm{B}$ are present in almost all retinal neurons except photoreceptors (Liu et al., 2011), it is possible that there may be a basal level of endogenous orexins in the mouse retina and retinal neurons function in an orexin-rich microenvironment. We first examined whether and how pupil constrictions in response to light steps ( $463 \mathrm{~nm}, 20 \mathrm{~s}$ ) were altered in WT C57BL/ 6 mice when retinal endogenous orexin activity was suppressed by intravitreal injection of $500 \mu \mathrm{M}$ TCS1102, an antagonist for both $\mathrm{OX}_{1} \mathrm{R}$ and $\mathrm{OX}_{2} \mathrm{R}$. In both control (treated with an equal volume of DMSO solution) and TCS1102-treated mice, pupillary constriction was increased by light steps of increasing irradiance (see the I-R curves in Fig. 1A1). However, TCS1102-treated animals showed an overall decrease in pupillary constriction, compared with control mice (two-way repeated-measures ANOVA, $F_{(1,13)}=5.382, p<0.05$; Sidak multiple comparison test, $p<0.05$ at $10.09 \log$ photons $/ \mathrm{cm}^{2} / \mathrm{s} ; n=10$ for control, $n=5$ for TCS1102). Figure $1 A 2$ shows representative images of the pupils of TCS1102treated and control WT mice. The PLR is composed of two components, driven by activation of melanopsin and rods/cones, respectively (Hattar et al., 2003). To precisely understand whether orexins may differentially affect these two components, we next explored the effects of orexin system perturbance on the melanopsin-mediated component in $r d / r d c l$ mice, wherein rods/cones were degenerated, and on the rod/cone-mediated component in Opn $4^{-1-}$ mice, in which melanopsin was knocked out. Because of the loss of rods/cones, PLRs exhibited markedly reduced sensitivity in $r d / r d c l$ mice compared with C57BL/6 mice; $10 \mu \mathrm{M}$ TCS1102 administration significantly attenuated pupillary constriction in $r d / r d c l$ mice, resulting in a clear downward scaling of the PLR I-R curve (two-way ANOVA, $F_{(1,20)}=17.81, p<0.001$; Sidak multiple comparison test, $p<0.0001$ at $13.59 \log$ photons $/ \mathrm{cm}^{2} / \mathrm{s}, p<0.01$ at 12.59 and $13.09 \log$ photons $/ \mathrm{cm}^{2} / \mathrm{s}, p<0.05$ at $12.09,14.09$, and $14.59 \log$ photons $/ \mathrm{cm}^{2} / \mathrm{s} ; n=10$ for control, $n=12$ for TCS1102) (Fig. 1B1,B2). Similarly, attenuation of pupillary constriction by $10 \mu \mathrm{M}$ TCS1102 was also observed in Opn $4^{-/-}$mice (two-way repeated-measures ANOVA, $F_{(1,11)}=8.551, p<0.05$; Sidak multiple 

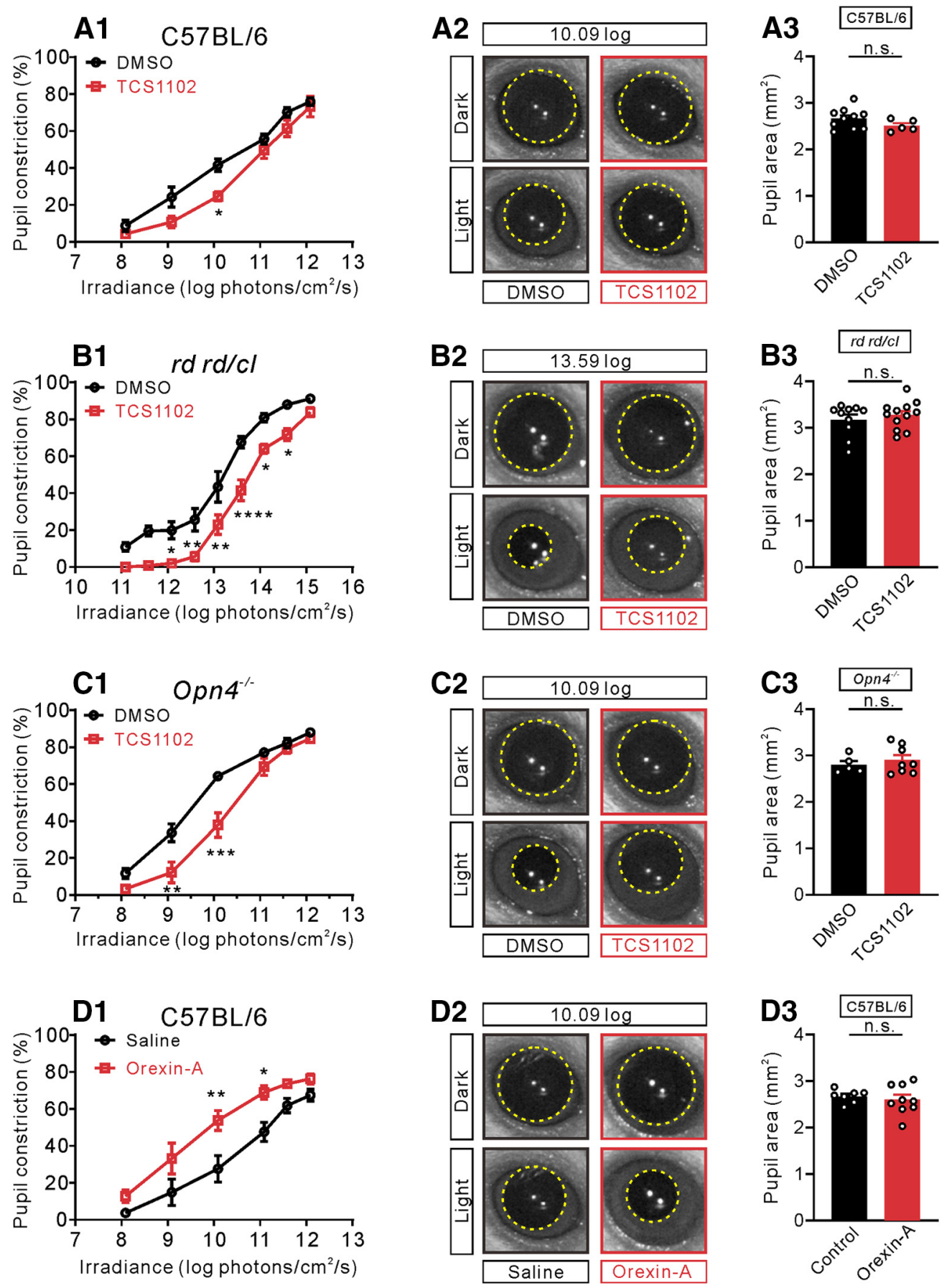

Figure 1. Effect of OXR antagonist and agonist on mouse PLRs and basal pupil areas. A1, B1, C1, I-R curves of PLRs, plotted based on percentage pupil constriction as a function of light intensity, in C57BL/6 (A1), rd/rd Cl (B1), and Opn4 ${ }^{-1-}(\mathbf{C} 1)$ mice that received an intravitreal injection of TCS1102 or vehicle. D1, I-R curves of PLRs derived from C57BL/6 mice treated with orexin-A or vehicle. $* p<0.05 . * * p<0.01$. $* * * p<0.001$. $* * * * p<0.0001$. $\mathbf{A 2}, \mathbf{B 2}, \mathbf{C 2}, \mathbf{D 2}$, Representative pupil images, captured during a $463 \mathrm{~nm}$ light step lasted for $20 \mathrm{~s}$ (intensity shown at the top of each panel), from TCS1102-/orexin-A- and vehicle-injected mice. A3, B3, C3, D3, Bar charts show that TCS1102 did not alter basal pupil areas in darkness in C57BL/6 (A3), $\mathrm{rd} r \mathrm{rd} / \mathrm{cl}(\boldsymbol{B 3})$, and $\mathrm{Opn4}^{-1-}$ mice (C3); and orexin-A did not affect the basal pupil area in C57BL/6 mice (D3). n.s., not significant.

comparison test, $p<0.001$ at $10.09 \log$ photons $/ \mathrm{cm}^{2} / \mathrm{s}, p<0.01$ at $9.09 \log$ photons $/ \mathrm{cm}^{2} / \mathrm{s} ; n=5$ for control, $n=8$ for TCS1102) (Fig. $1 C 1, C 2)$.

The above results imply that orexins intensify pupillary constriction, thus making the pupil smaller in size in response to light. We found that following intravitreal injection of orexin-A at a dose close to that induces robust activation of OXRs in central neurons $(15.87 \mu \mathrm{M}), \mathrm{C} 57 \mathrm{BL} / 6$ mice showed enhanced pupillary constriction in response to light steps (Fig. 1D1), resulting in a significant upward scaling of the I- $\mathrm{R}$ curve relative to that of vehicle-treated control mice (two-way repeated-measures ANOVA, $F_{(1,14)}=10.55, p<$ 0.01 ; Sidak multiple comparison test, $p<0.01$ at $10.09 \log$ photons $/ \mathrm{cm}^{2} / \mathrm{s}, p<0.05$ at $11.09 \log$ photons $/ \mathrm{cm}^{2} / \mathrm{s} ; n=7$ for saline-treated control animals, $n=9$ for orexin-A-treated animals). Figure 1D2 presents representative pupil images showing the distinct constriction amplitudes of orexin-Atreated and control mice. 
We also examined whether TCS1102 and orexin-A could affect basal pupil areas measured in complete darkness for at least $10 \mathrm{~s}$. Intravitreal injection of TCS1102 did not significantly alter the basal pupil size in C57BL/6, $r d r d / c l$, and $O p n 4^{-1-}$ mice, nor did orexin-A change the basal pupil area in C57BL/6 mice (all $p$ values $>0.05$; Mann-Whitney $U$ test in Fig. $1 B 3$, unpaired $t$ test with Welch's correction in Fig. 1A3,C3,D3). It seems likely that orexins modulate the PLR by boosting the light-induced pupil dynamic constriction, rather than adjusting the setting of the basal level of the PLR in the dark.

\section{Orexin-A increases the intrinsic light-evoked spiking rates of M2 cells}

The PLR in mice is principally mediated by ipRGCs (Guler et al., 2008). It is known that pupillary constriction is intensified as spiking rates of ipRGCs are increased (Keenan et al., 2016; Milosavljevic et al., 2018). Because M1/M2 cells mostly project to the OPN (Baver et al., 2008) and pupillary constriction is minimized when light-induced GC spiking is blocked by TTX (Webb et al., 2013), it was reasonable to explore how the activity of M1/ M2 cells could be modulated by orexins.

We first investigated I-R relations of the "intrinsic," melanopsin-driven light-evoked spiking rates of M2 cells with and without TCS1102 in whole-mount retinas. WT Opn4-tdTomato mice were used for this experiment, in which ipRGC somata are specifically labeled with red fluorescence protein (Do et al., 2009). We targeted cells exhibiting small somata with bright red fluorescence, characteristic of M2 and M1 cells, for recording. M2 cells can be reliably distinguished based on their distinct dendritic profiles by LY included in the recording pipettes (Fig. $2 A$ ). These cells exhibited wide dendritic fields and sparse dendrites stratifying exclusively in the ON sublamina of the IPL, somewhat below the ON ChAT-labeled band (Schmidt and Kofuji, 2009). These cells could not be M4 cells as evidenced by the absence of immunolabeling of SMI-32, a marker for M4 cells (Schmidt et al., 2014), in all 18 cells examined (a representative example is shown in Fig. 2B). They are quite different morphologically from M1 cells, which are "OFF-stratifying" cells in the retina, and from M5 cells, which are also "ON-stratifying" neurons but are characterized by small and bushy dendritic fields (Stabio et al., 2018), as well as from M3/M6 cells which possess bistratified dendrites (Schmidt and Kofuji, 2011; Quattrochi et al., 2019).

During these experiments, the retinas were perfused with a cocktail containing $50 \mu \mathrm{M} \mathrm{L}-\mathrm{AP} 4$ (metabotropic glutamate receptor 6 agonist), $30 \mu \mathrm{M}$ D-AP5 (NMDA receptor antagonist), and $40 \mu \mathrm{M}$ DNQX (AMPA/kainate receptor antagonist) to specifically block glutamatergic transmission (Fig. 2C). Therefore, the light-induced responses to a $2 \mathrm{~s} 475 \mathrm{~nm}$ light step series at 11.52 $15.89 \mathrm{log}$ photons $/ \mathrm{cm}^{2} / \mathrm{s}$, recorded in cell-attached mode, were exclusively driven by melanopsin. In the absence of TCS1102 (control), a light step exceeding melanopsin activation threshold induced robust spike discharges in a group of M2 cells, and these spikes persisted during light exposure and then decayed slowly, lasting over for tens of seconds, as reported previously (Berson et al., 2002; Zhao et al., 2014) (Fig. 2D1, top). Administration of TCS1102 $(10 \mu \mathrm{M})$ to another group of M2 cells led to markedly attenuated discharges (Fig. 2D1, bottom). The spiking rates, measured during a $60 \mathrm{~s}$ period after light onset in M2 cells, were increased as a function of light intensity in both control and TCS1102-treated M2 cells. TCS1102 administration resulted in a downward scaling of the I-R curve (two-way ANOVA, $F_{(1,9)}=6.382, p<0.05$; Sidak multiple comparison test, $p<0.01$ at $13.84,14.81 \log$ photons $/ \mathrm{cm}^{2} / \mathrm{s}, p<0.05$ at $15.89 \log$ photons/ $\mathrm{cm}^{2} / \mathrm{s} ; n=5$ for control, $n=5$ for TCS1102) (Fig. 2D2). These results were similar to those observed in the melanopsin-driven PLR (Fig. 1B1), suggesting that orexins may modulate mouse PLR by changing the outputs of M2 cells.

Next, we tested the effect of orexin-A on the intrinsic lightevoked spiking rates of $\mathrm{M} 2$ cells in response to a $475 \mathrm{~nm}$ test light pulse (13.84 log photons $\left./ \mathrm{cm}^{2} / \mathrm{s}, 2 \mathrm{~s}\right)$. Light-induced responses were analyzed during short ( $2 \mathrm{~s})$ and long (60s) periods after light onset. When $500 \mathrm{~nm}$ orexin-A was applied to the retina, a significant increase in the spiking rate of M2 cells was seen (Fig. $2 E 1)$. On average, the spiking rate of $\mathrm{M} 2$ cells in the presence of $500 \mathrm{~nm}$ orexin-A was increased from $7.07 \pm 0.83 \mathrm{~Hz}$ to $11.42 \pm$ $1.18 \mathrm{~Hz}$ (Fig. 2E2) and from $2.85 \pm 0.53 \mathrm{~Hz}$ to $7.29 \pm 0.80 \mathrm{~Hz}$ (Fig. 2E3) for short and long periods (Wilcoxon signed-rank test, $p<0.001$ in both cases, $n=19$ ).

The orexin-A-induced effect was concentration-dependent. Figure 2F1, F2 shows the dose-response relations between orexinA and M2 cell spiking rates for short and long periods. To avoid any layering effects of different concentrations, each cell was treated with orexin-A of only one concentration, and data from four different cell groups $(50,100,500$, and $1000 \mathrm{nM})$ were pooled to generate the dose-response functions. No significant potentiation of lightinduced spiking rates was seen with application of $50 \mathrm{~nm}$ orexin-A (105.45 $\pm 3.70 \%$ and $102.21 \pm 7.55 \%$ of control for short and long periods, respectively, $p>0.05$ in both cases, $n=3$ ). However, the average spiking rate for the test light step was significantly potentiated by orexin- $\mathrm{A}$ in a dose-dependent manner for short period data when the concentration was larger than $100 \mathrm{~nm}$ (100 nм: $124.83 \pm 10.2 \%$ of control, $p<0.05, n=7 ; 500 \mathrm{nM}: 155.00 \pm 9.81 \%$ of control, $p<0.001, n=12 ; 1000$ nM: $178.60 \pm 15.42 \%$ of control, $p<0.05, n=3$ ) (Fig. 2F1). Similar results were obtained for long-period data (Fig. 2F2).

To determine what subtype(s) of OXRs may mediate the orexin effect pharmacologically, we tested the effects of two distinct OXR antagonists on the intrinsic light-evoked spiking rate of M2 cells. As shown in Figure 2G1-G3, SB334867 (5 $\mu \mathrm{M})$, a selective antagonist for $\mathrm{OX}_{1} \mathrm{R}$, significantly reduced the intrinsic light-evoked spiking rate of M2 cells from $18.07 \pm 2.35 \mathrm{~Hz}$ to $14.06 \pm 2.20 \mathrm{~Hz}(p<0.001, n=7)$ and from $8.70 \pm 2.40 \mathrm{~Hz}$ to $6.42 \pm 2.05 \mathrm{~Hz}(p<0.01, n=7)$, for short and long period data, respectively. In contrast, TCS OX229, a selective antagonist for $\mathrm{OX}_{2} \mathrm{R}$, did not change the spiking rate $(p>0.05$ for both short and long period data, $n=7$; Fig. $2 H 1-H 3)$. These results suggested a role of retinal endogenous orexins in modulating $\mathrm{M} 2$ cells, and raised a possibility that $\mathrm{OX}_{1} \mathrm{R}$, but not $\mathrm{OX}_{2} \mathrm{R}$, may be involved in the orexin effect.

This possibility was strengthened by the experiment showing that orexin-A (500 nM) failed to increase the intrinsic lightevoked spiking rate of M2 cells pretreated with SB334867. In this experiment, we first perfused the preparations with SB334867 $(5 \mu \mathrm{M})$, which reduced the spiking rate to a steady level. In the presence of SB334867, $500 \mathrm{~nm}$ orexin-A no longer potentiated the spiking rates $(p>0.05$ for both short and long periods data, $n=5$; Fig. 2I1-I3). In contrast, in the presence of TCS OX229 $(5 \mu \mathrm{M})$, orexin-A persisted to increase intrinsic light-evoked spiking rates $(16.17 \pm 1.49$ vs $11.63 \mathrm{~Hz} \pm 1.26 \mathrm{~Hz}$ for short period data; $9.05 \pm 1.45 \mathrm{~Hz}$ vs $4.63 \pm 0.92 \mathrm{~Hz}$ for long period data; $p<0.001$ in both cases, $n=12$; Fig. 2J1-J3).

\section{Orexin-A enhances M2 cell excitability without changing melanopsin-based photocurrents}

The next question we sought to answer is how activation of $\mathrm{OX}_{1} \mathrm{Rs}$ increases the light-evoked spiking rate. Because the 

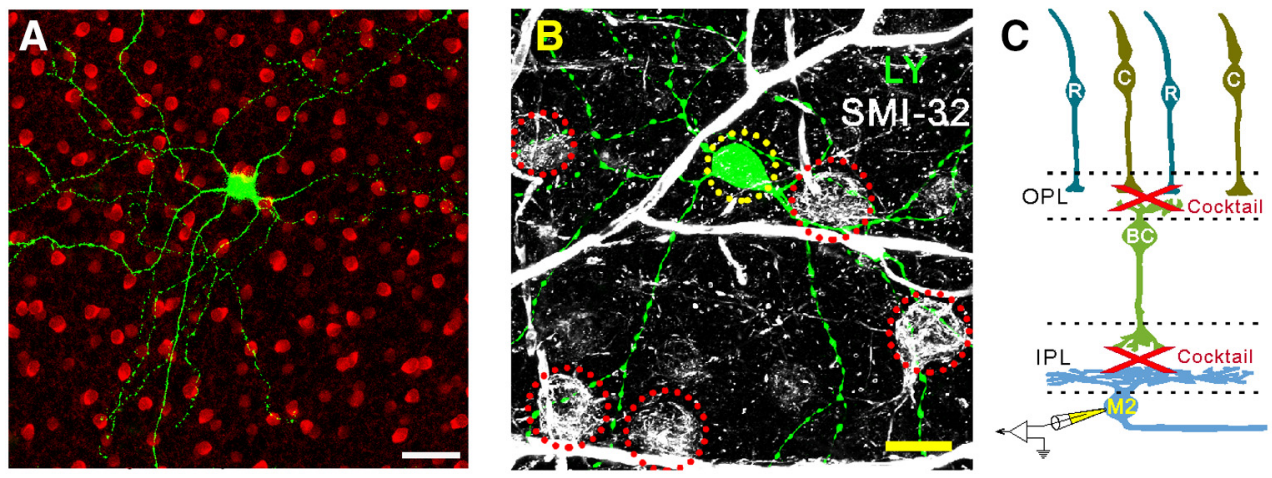

INL
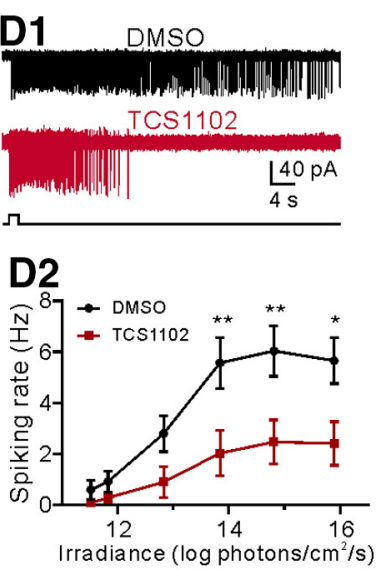

E1

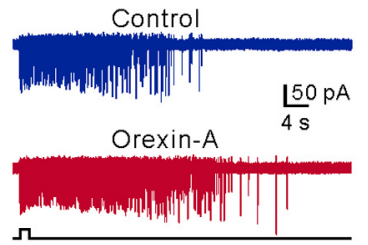

G1

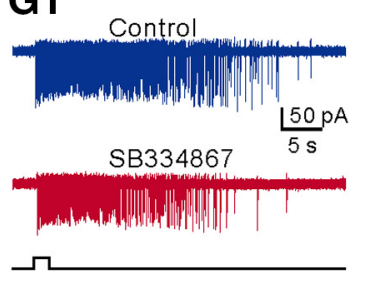

11

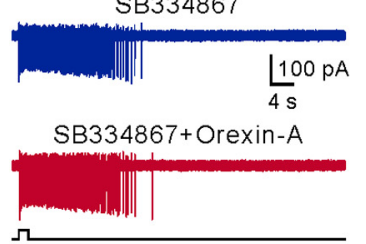

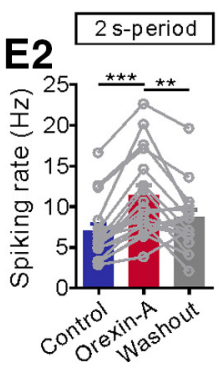

G2
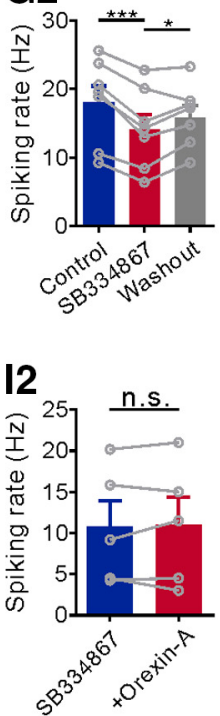
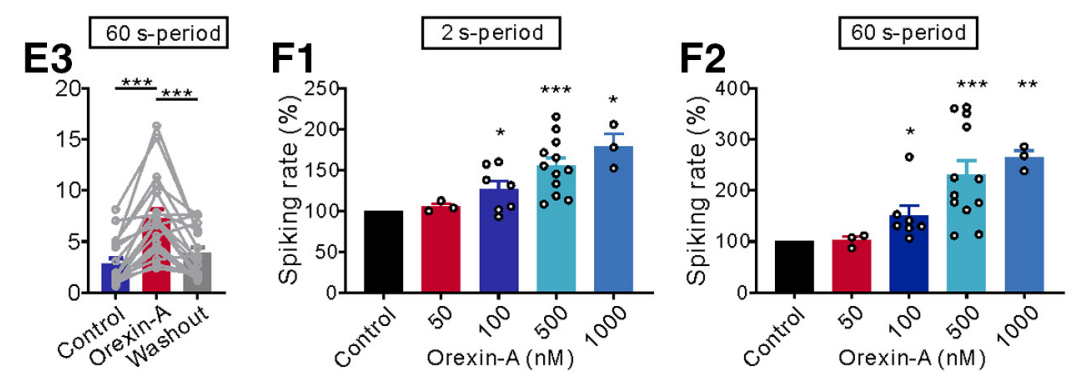

G3
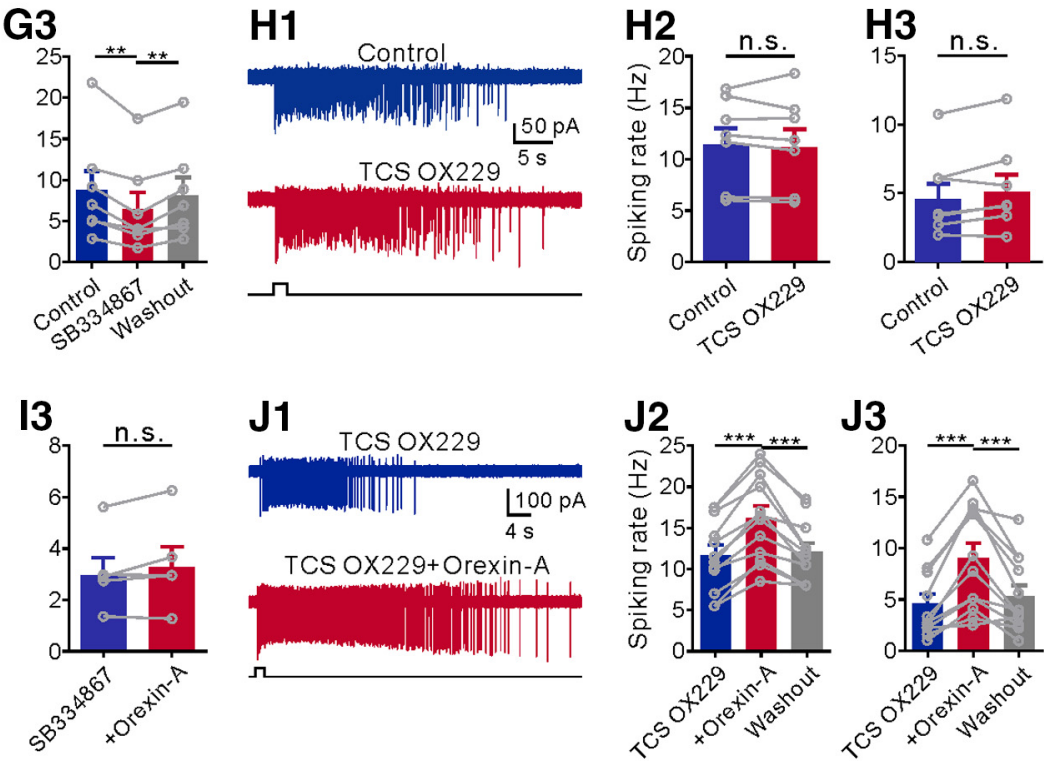

Figure 2. Orexin-A increases intrinsic light-evoked spiking rates of M2 cells. $A$, Confocal microphotographs of a whole-mount mouse retina, showing an M2 cell filled with LY (green) coimmunolabeled with ChAT (red). Side view of the same cell (below), showing that dendritic branches of the M2 cell stratify solely in the ON sublamina of the IPL. Scale bar, $40 \mu \mathrm{m}$. GCL, GC layer; INL, inner nuclear layer; ON, ON sublamina; OFF, OFF sublamina. $B$, Representative microphotograph showing that SMI-32 signals were not seen in the LY-filled ipRGC. Yellow circle represents the soma of the LY-filled M2 cell. Red circles represent SMI-32-positive somata. Scale bar, $20 \mu \mathrm{m}$. C, Schematic illustration showing how the intrinsic light responses of ipRGCS were recorded. $\mathrm{R}$, Rod; C, cone; BC, bipolar cell; OPL, outer plexiform layer. D1, Representative intrinsic light-evoked spiking responses of an M2 cell recorded in cell-attached mode, showing that an increase in spiking rate was reduced by TCS1102 $(10 \mu \mathrm{M})$. Stimulation bar represents the timing of the light pulse $\left(2 \mathrm{~s}, 475 \mathrm{~nm}\right.$ flash with an intensity of $13.84 \mathrm{log}$ photons $\left./ \mathrm{cm}^{2} / \mathrm{s}\right)$. D2, Effect of TCS1102 on I-R relations of intrinsic light-evoked spiking rates of M2 cells. TCS1102 reduced the rates evoked by light steps of three higher irradiances (13.84, 14.81, and 15.89 log photons/ $\mathrm{cm}^{2} / \mathrm{s}$ ). Data were obtained when the preparations were perfused with Ames' medium containing glutamatergic blockers (L-AP4, DNQX, and D-AP5). Data obtained in the perfusion medium with DMSO instead of TCS1102 were used as control. E1, Representative intrinsic light-evoked spiking responses of another M2 cell recorded in cell-attached mode, showing that an increase in spiking rate was caused by orexin-A (500 nM). E2, E3, Bar charts showing that orexin-A significantly increased the average firing rates of M2 cells for short (2 s) (E2) and long (60 s) periods (E3) after light onset. $\boldsymbol{F 1}, \boldsymbol{F 2}$, Orexin-A dose-dependently increased the intrinsic light-evoked spiking rates of M2 cells for short (F1) and long periods (F2) after light onset. G1, Representative recordings show that $5 \mu \mathrm{m}$ SB334867, a selective $0 X_{1} R$ antagonist, decreased the light-evoked spiking rate of an M2 cell. G2, G3, Bar charts show that SB334867 significantly decreased the average spiking rates of M2 cells for short (G2) and long periods (G3) after light onset. $\boldsymbol{H 1}$, Representative recordings show that TCS $0 X 229(5 \mu \mathrm{M})$, a selective $0 \mathrm{X}_{2} \mathrm{R}$ antagonist, hardly changed the intrinsic light-evoked spiking rate of another M2 cell. $\mathbf{H 2}, \mathbf{H 3}$, Bar charts summarize the effect of TCS OX229 on the average spiking rates of M2 cells. II, The intrinsic light response of an M2 cell was no longer increased by orexin-A (500 nм) in the presence of $5 \mu \mathrm{m} \mathrm{SB334867.} \mathrm{12,} \mathrm{I3,} \mathrm{Bar} \mathrm{charts} \mathrm{of} \mathrm{pooled} \mathrm{data} \mathrm{show} \mathrm{that} \mathrm{SB334867} \mathrm{completely} \mathrm{blocked} \mathrm{the} \mathrm{orexin-A} \mathrm{effect} \mathrm{in} \mathrm{M2}$ cells. J1, Orexin-A (500 nM) persisted to increase the light-evoked spiking rate of an M2 cell during perfusion of $5 \mu \mathrm{m}$ TCS 0X229. J2, J3, Bar charts of pooled data show that TCS 0X229 did not abolish the orexin-A effect in M2 cells. $* p<0.05 . * * p<0.01$. $* * * p<0.001$. n.S., not significant. 
spiking rate of $\mathrm{M} 2$ cells depends on the amplitude of the melanopsin-based photocurrent, a measure of melanopsin phototransduction, and/or on intrinsic membrane excitability (Kowalski et al., 2016; Sonoda et al., 2018), we tested the effects of orexin-A on these two parameters.

Melanopsin-based photocurrents were recorded in whole-cell voltage-clamp mode, with bath perfusion of the cocktail for blocking rod/cone-driven synaptic inputs and TTX for silencing action currents. As shown in Figure $3 A$, the wholecell photocurrent recorded from an M2 cell in the presence of $500 \mathrm{~nm}$ orexin-A was hardly different from the control. The average peak current collected from seven M2 cells was not affected by orexin-A [21.56 $\pm 2.15 \mathrm{pA}$ (orexin-A) vs $22.15 \pm 2.47 \mathrm{pA}$ (control), $p>0.05$ ] (Fig. $3 B$ ), suggesting no involvement of melanopsin phototransduction in the orexinA-induced increase in spiking rates.

Spontaneous spiking rates generated in darkness may be regarded as an indicator of the excitability of M2 cells (Nelson et al., 2003). Orexin-A at $500 \mathrm{~nm}$ increased the M2 cell spontaneous spiking rates, both in the control (Ames' medium) condition $(8.18 \pm 0.88 \mathrm{~Hz}$ vs $2.72 \pm 0.31 \mathrm{~Hz}, p<0.01, n=6$; Fig. $3 C$ ) and in the presence of the cocktail $(6.36 \pm 2.09 \mathrm{~Hz}$ vs $0.3 \pm 0.3 \mathrm{~Hz}, p<0.05$, $n=5$; Fig. $3 D$ ), implying an increase of the cell excitability. Orexin-A-induced hyperexcitability is attributed to a direct postsynaptic action of orexin-A on M2 cells, because the effect survived when glutamatergic transmission was blocked by the cocktail (Fig. 3D). Figure $3 E$ shows how the spontaneous spiking rate changed as a function of time from the beginning of a 2 min application of $500 \mathrm{~nm}$ orexin-A. As reported in other central neurons (J. Zhang et al., 2011), an increase in the spiking rate was detected almost immediately after orexin-A administration and peaked at $\sim 3$ min ( $313.58 \pm 33.43 \%$ of control, $p<0.001, n=6$ ); it then gradually decayed to the basal level.

We further examined the responses of M2 cells to injections of depolarizing currents of increasing amplitudes, with the membrane potential maintained at $-83 \pm 5 \mathrm{mV}$ with appropriate holding currents to suppress spontaneous spiking (Fig. $3 F$ ). In Figure $3 G$, the average spiking rates are plotted against the amplitudes of depolarizing currents. The rates were markedly higher with than without orexin-A (500 nM) at almost all the stimuli tested $(p<0.05, p<0.001, p<0.001$, and $p<0.01$ at 50 , 75,100 , and $125 \mathrm{pA}$, respectively). These results demonstrated that orexin-A significantly increased the intrinsic excitability of M2 cells.

Orexin-A increases M2 cell excitability by depolarizing the cell membrane

To identify the mechanism underlying the increased intrinsic excitability of M2 cells caused by orexin-A, we examined the
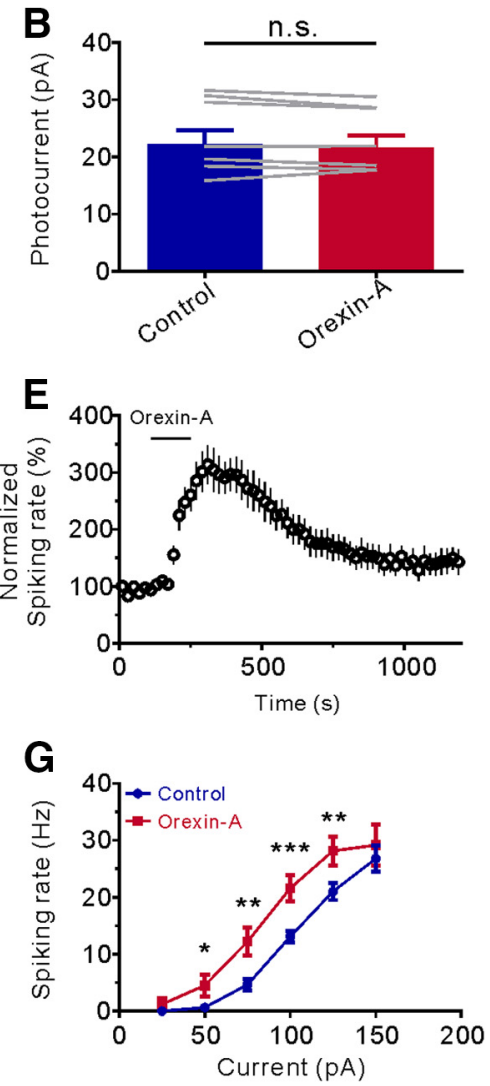

3. Effects of orexin-A on photocurrents, spontaneous and evoked spiking rates of M2 cells. $\boldsymbol{A}$, Photocurrents of an (he presence of the glutamatergic blocker cocktail $(\boldsymbol{D})$. $\boldsymbol{E}$, Spontaneous spiking rates relations. $* p<0.05$. $* * p<0.01$. $* * * p<0.001$. n.s., not significant.

effect of orexin-A on several membrane parameters of M2 cells, which have been demonstrated to be associated with the cell excitability (Sonoda et al., 2018). Bath perfusion of orexin-A (500 $\mathrm{nM}$ ) depolarized the M2 cell and changed the resting membrane potential from $-61.5 \pm 2.05 \mathrm{mV}$, which is quite comparable with those reported in several previous studies (Schmidt and Kofuji, 2010; Emanuel et al., 2017), to $-56.17 \pm 2.52 \mathrm{mV}(p<0.05$, Wilcoxon signed-rank test, $n=6$; Fig. $4 A, E)$. Similar to the orexin-A-induced increase in the spontaneous spiking rate (Fig. $3 C, D)$, the orexin-A-induced depolarization $(5.33 \pm 0.72 \mathrm{mV}$, $n=6)$ was maintained at a comparable amplitude during glutamatergic cocktail perfusion $(5.0 \pm 0.27 \mathrm{mV}$, Dunn's multiple comparison test, $p>0.05, n=17$; Fig. $4 B, F)$. Moreover, it was not changed by the addition of the chemical synapse blocker $\mathrm{CoCl}_{2}(1 \mathrm{~mm})$ (4.81 $\pm 0.27 \mathrm{mV}$, Dunn's multiple comparison test, $p>0.05, n=7$; Fig. $4 C, F)$ or the gap junction blocker carbenoxolone $(25 \mu \mathrm{M})$ $(4.79 \pm 0.52 \mathrm{mV}$, Dunn's multiple comparison test, $p>0.05, n=5$; Fig. $4 D, F)$. Furthermore, the orexin-A-induced depolarization was unchanged by $5 \mu \mathrm{M}$ TCS OX229 (4.77 $\pm 0.43 \mathrm{mV}$, Dunn's multiple comparison test, $p>0.05, n=6$; Fig. $4 G, I)$, but markedly reduced by coapplication of $5 \mu \mathrm{M}$ SB334867 $(0.87 \pm 0.32 \mathrm{mV}$, Dunn's multiple comparison test, $p<0.001, n=6$; Fig. $4 H, I)$, suggesting that such membrane depolarization is mediated by $\mathrm{OX}_{1} \mathrm{R}$. Thus, the possibility that the orexin-A-induced depolarization was because of the effect of orexin-A on presynaptic neurons and/or cells 

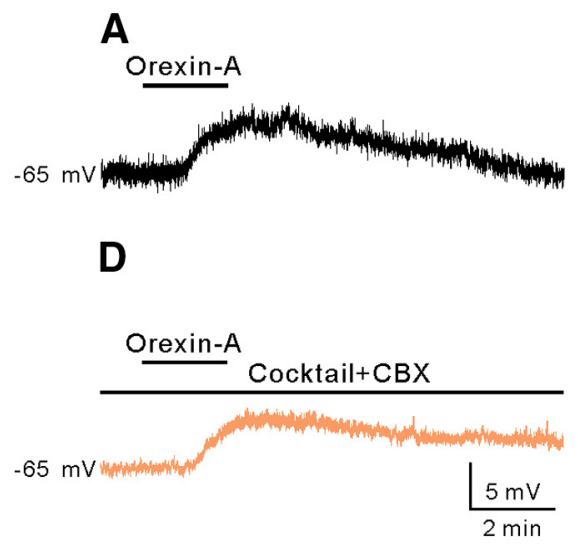

G

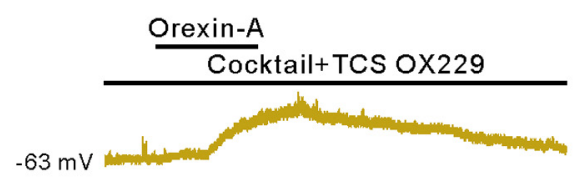

B
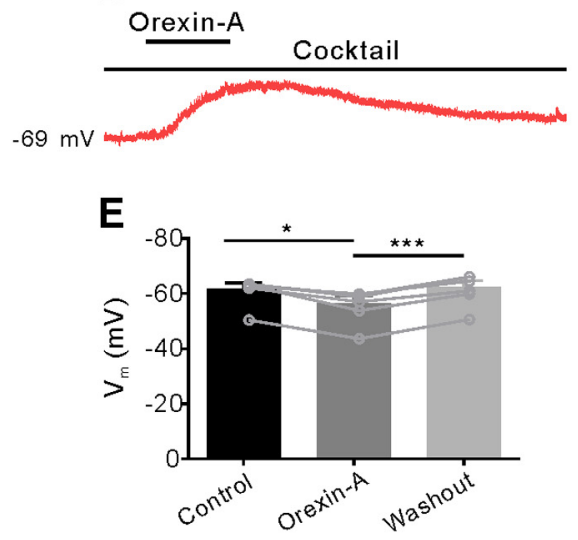

H

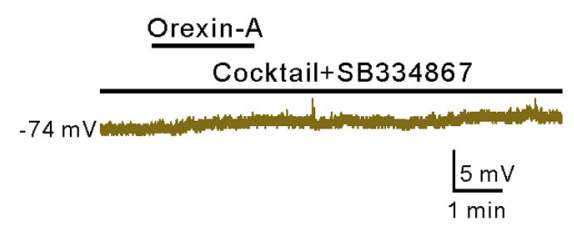

J

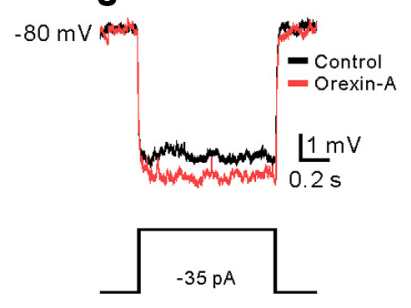

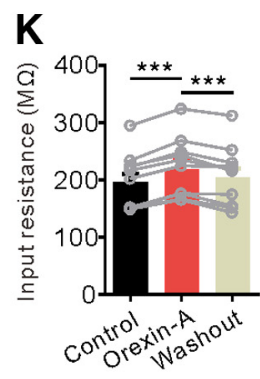

C

Orexin-A

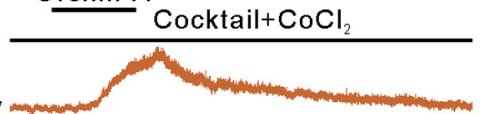

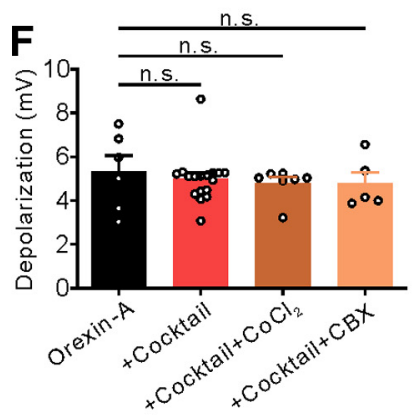

I

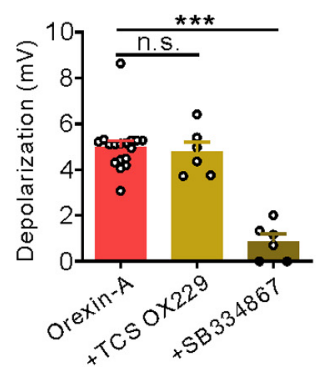

M

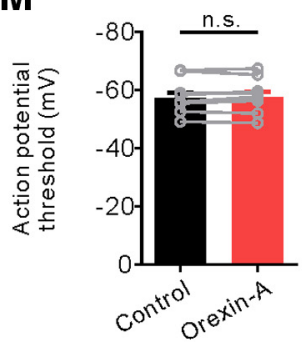

Figure 4. Orexin-A induced membrane depolarization of $M 2$ cells by direct activation of postsynaptic $O X_{1} R s$. $A-D$, Representative recordings from four different $M 2$ cells, showing the orexin-A (500 nM)-induced depolarizations obtained in normal Ames' medium $(\boldsymbol{A})$, in the presence of the cocktail (L-AP4, DNQX, D-AP5, and TTX) $(\boldsymbol{B})$, in cocktail $+\mathrm{CoCl}_{2}(\boldsymbol{C})$, and in cocktail + carbenoxolone (CBX) (D). $\boldsymbol{E}$, Bar chart compares the membrane potentials of M2 cells in Ames' medium and in the presence of orexin-A. $\boldsymbol{F}$, Pooled data show that the average orexin-A-induced depolarization of M2 cells was not changed in size by the blockade of chemical and electrical synapses. $\boldsymbol{G}, \boldsymbol{H}$, Traces show that orexin-A-induced depolarization was profoundly suppressed by SB334867 (H), but was unchanged by the addition of TCS 0X229 (G). I, Bar chart summarizes the effects of SB334867 and TCS 0X229 on the orexin-A-induced depolarization of M2 cells. $J$, Current-clamp recordings from an M2 cell, showing the voltage responses to a $35 \mathrm{pA}$ hyperpolarizing current injection, in the absence and presence of $500 \mathrm{nM}$ orexin-A. $\boldsymbol{K}$, Bar chart of pooled data shows that orexin-A significantly increased the input resistances of M2 cells. L, Action potential waveform of an M2 cell in normal Ames' medium (left) and in the presence of $500 \mathrm{~nm}$ orexin-A (right). Dotted line indicates the action potential threshold. $\boldsymbol{M}$, Grouped data show that orexin-A did not influence the action potential threshold of $M 2$ cells. $* p<0.05$. $* * * p<0.001$. n.S., not significant.

electrically coupled to M2 cells could be ruled out; rather, it is a consequence of the direct activation of $\mathrm{OX}_{1} \mathrm{Rs}$ in these cells, which in turn modifies a series of intrinsic membrane properties.

The changes in input resistance, another important membrane parameter, were assayed by measuring the voltage responses to $-35 \mathrm{pA}$ hyperpolarizing current steps injected in M2 cells in the absence/presence of $500 \mathrm{~nm}$ orexin-A. The input resistance was increased significantly by orexin-A from $195.77 \pm 15.31 \mathrm{M} \Omega$, a value close to previous reports (Schmidt and Kofuji, 2009), to $218.70 \pm 16.48 \mathrm{~m} \Omega(p<0.001, n=10$; Fig. $4 J, K)$, implying the closure of certain channels and reduced leak conductance, which would in turn increase the intrinsic excitability (Kowalski et al., 2016; Sonoda et al., 2018). Orexin-A did not change the action potential threshold of $\mathrm{M} 2$ cells $(-57.17 \pm 1.95 \mathrm{mV}$ in control Ames' medium vs $-57.50 \pm 1.95 \mathrm{mV}$ with orexin-A, $p>0.05, n=9$; Fig. $4 L, M)$.
However, orexin-A depolarized M2 cells, such that the resting membrane potential of these cells became closer to the unchanged action potential threshold, indicating higher intrinsic excitability.

Inward rectifier potassium channels and nonselective cation channels (NSCCs) are both involved in orexin-A-induced depolarization

We investigated ionic mechanisms underlying the orexin-Ainduced depolarization through two sets of experiments. In the first set of experiments, relations of whole-cell currents of M2 cells in response to voltage ramps from -153 to $27 \mathrm{mV}(d V /$ $d t=90 \mathrm{mV} / \mathrm{s})$ ( $I-V$ relations) in the presence and absence of orexin-A (500 nM) were determined (Fig. $5 A$ ). In a small fraction of M2 cells probed ( 3 of 17, 17.6\%; Fig. $5 B$ ), orexin-A induced an inward current reversing at $-112.0 \pm 9.5 \mathrm{mV}$, which was close to 
A
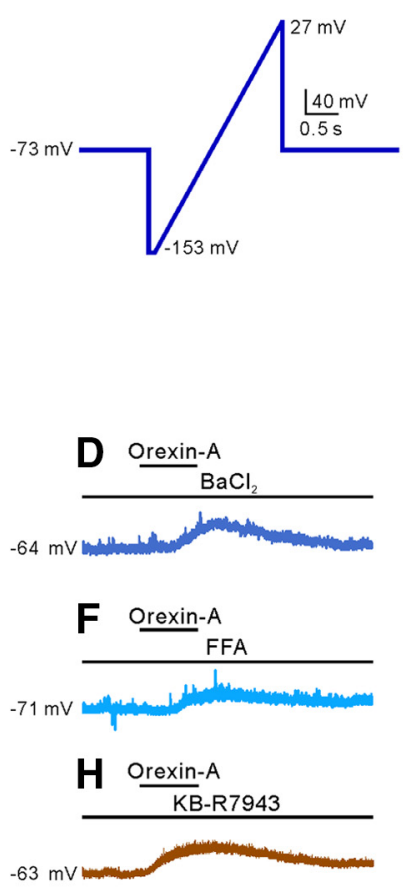

B
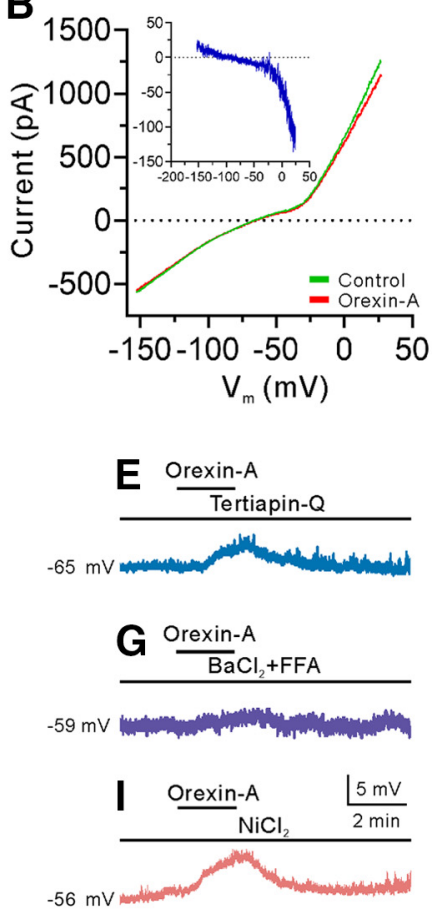
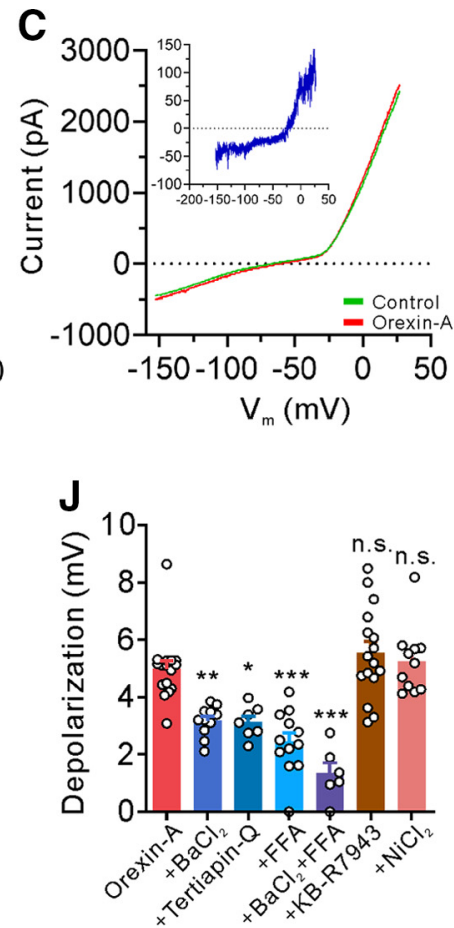

Figure 5. Multiple ionic mechanisms underlying the orexin-A-induced depolarization in M2 cells. $\boldsymbol{A}$, Voltage protocols for investigating the $I-V$ relations of $M 2$ cells. $\boldsymbol{B}, \boldsymbol{C}$, Representative $\mathbf{I} V$ relation changes observed in two subsets of $\mathrm{M} 2$ cells tested; the orexin-A-induced current reversed in polarity near the equilibrium potential of $\mathrm{K}^{+}$channels $(\boldsymbol{B})$ and NSC(s $(\boldsymbol{C})$, respectively. Insets, Net orexin-A-induced currents calculated by subtracting $I-V$ curves obtained in control condition from those obtained in the presence of orexin-A. $D-I$, Representative current-clamp recordings showing orexin-A (500 nM)-induced depolarization of $\mathrm{M} 2$ cells in Ames' solution containing the glutamatergic cocktail, along with Ba ${ }^{2+}\left(\mathrm{K}^{+}\right.$channel blocker, 1 mm, $\left.\mathbf{D}\right)$, Tertiapin- $\mathrm{Q}$

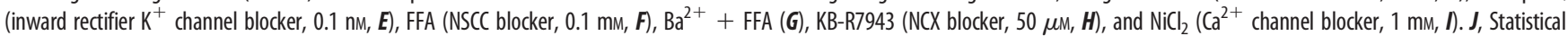
comparison of the effects of various ion channel blockers on orexin-A-induced depolarization of $\mathrm{M} 2$ cells. $* p<0.05$. $* * p<0.01$. $* * * p<0.001$. n.s., not significant.

the calculated equilibrium potential of $\mathrm{K}^{+}$channels $(-89.18$ $\mathrm{mV}$ ), suggesting a major contribution of $\mathrm{K}^{+}$channels to this current. However, in a majority of them (11 of 17, 64.7\%), the orexin-A-induced current reversed at $-28.9 \pm 2.3 \mathrm{mV}$, which was closer to the equilibrium potential of NSCC (Fig. $5 C$ ), thus arguing for mixed ionic mechanisms involved in the orexin-Ainduced excitation on M2 cells. The $I$ - $V$ curves of the remaining three cells ( 3 of $17,17.6 \%$ ) did not reverse within the entire voltage ramp range, probably because of the imperfect space clamp of M2 cells, which are reported to be gap-junction coupled to neighboring neurons (Caval-Holme et al., 2019).

The ionic basis of the effect of orexin-A was further explored using various ion channel blockers. The orexin-A-induced depolarization was significantly suppressed by $1 \mathrm{mM} \mathrm{Ba}^{2+}$, a nonselective blocker of $\mathrm{K}^{+}$channels, from $5.0 \pm 0.27 \mathrm{mV} \quad(n=17)$ (control) to $3.17 \pm 0.16 \mathrm{mV}(n=11)$ (Dunn's multiple comparison test, $p<0.01$; Fig. $5 D, J)$, suggesting the involvement of $\mathrm{K}^{+}$ channels. The inward rectifier potassium (Kir) channel-specific blocker Tertiapin-Q (0.1 mM) also suppressed the depolarization to $3.13 \pm 0.21 \mathrm{mV}$ (Dunn's multiple comparison test, $p<0.05, n=7$; Fig. $5 E, J)$, an effect similar to that caused by $\mathrm{Ba}^{2+}$ (unpaired $t$ test with Welch's correction, $p>0.05$ ), suggesting that the closure of Kir channel made a large contribution to the $\mathrm{Ba}^{2+}$-sensitive excitatory component. FFA $(0.1$ $\mathrm{mm}$ ), an NSCC blocker, also suppressed depolarization significantly $(2.44 \pm 0.2 \mathrm{mV}$; Dunn's multiple comparison test, $p<0.001, n=12$; Fig. $5 F, J)$, suggesting that NSCCs may contribute to the membrane depolarization of M2 cells induced by orexin-A. Furthermore, when $\mathrm{Ba}^{2+}$ was coapplied with FFA (Fig. 5G,J), the orexin-A-induced depolarization was reduced to a very low level $(1.33 \pm 0.93 \mathrm{mV}$; Dunn's multiple comparison test, $p<0.001, n=6)$.
Although it was previously reported that sodium-calcium exchangers (NCXs) and $\mathrm{Ca}^{2+}$ channels were both involved in the membrane depolarization caused by orexin administration (Eriksson et al., 2001), neither the NCX blocker KB-R7943 (50 $\mu \mathrm{M})$ nor the $\mathrm{Ca}^{2+}$ channel blocker $\mathrm{NiCl}_{2}$ (1 mM; T- and L-type $\mathrm{Ca}^{2+}$ channels, both abundantly expressed by GCs, are known to be blocked at this concentration) (Mukherjee et al., 2015) significantly altered the orexin-A-induced depolarization of M2 cells $\left(5.54 \pm 0.40 \mathrm{mV}\right.$ for KB-R7943, $n=16 ; 5.25 \pm 0.35 \mathrm{mV}$ for $\mathrm{NiCl}_{2}$, $n=11$; Dunn's multiple comparison test, $p>0.05$ in both cases), compared with the depolarization $(5.00 \pm 0.27 \mathrm{mV}, n=17)$ recorded in the control condition (in the presence of the glutamatergic blocker cocktail, but without KB-R7943 and $\mathrm{NiCl}_{2}$ ) (Fig. $5 H-J)$. Thus, it seems that NSCCs, together with Kir channels, are largely responsible for orexin-A-induced depolarization in $\mathrm{M} 2$ cells, whereas NCXs and $\mathrm{Ca}^{2+}$ channels were not associated with this action.

\section{Orexin-A increases the extrinsic light-evoked spiking rate of M2 cells}

The effect of orexin-A on "the extrinsic," synaptically driven light responses of M2 cells was tested at $9.61 \log$ photons $/ \mathrm{cm}^{2} / \mathrm{s}$, which is lower than the threshold for melanopsin activation (Dacey et al., 2005; Zhao et al., 2014). Following orexin-A (500 nM) administration, the extrinsic light-evoked spiking rate of M2 cells during a $3 \mathrm{~s}$ period after light onset, recorded under cell-attached mode in normal Ames' medium, was increased from $12.33 \pm$ $1.96 \mathrm{~Hz}$ to $19.02 \pm 2.75 \mathrm{~Hz}(p<0.01, n=6$; Fig. $6 A, B)$. However, orexin-A had no effect on the extrinsic photocurrent of M2 cells [192.35 $\pm 45.92 \mathrm{pA}$ (orexin-A) vs $192.82 \pm 45.55 \mathrm{pA}$ (control), $p>0.05, n=8$ ] (Fig. 6C,D). Similar experiments were performed 

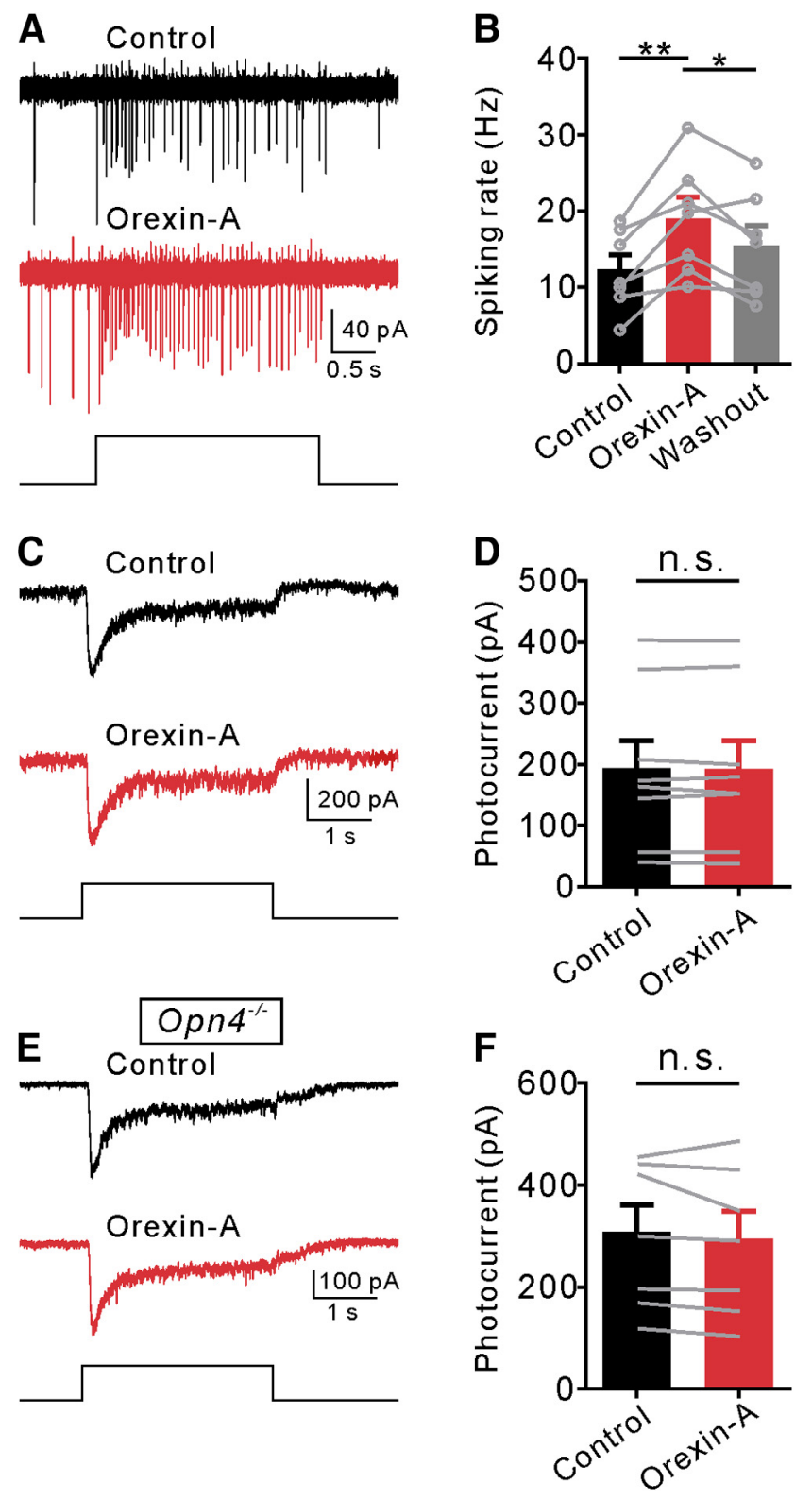

Figure 6. Orexin-A increases extrinsic light-evoked spiking rates but has no effect on extrinsic photocurrents of $\mathrm{M} 2$ cells. $\boldsymbol{A}$, Extrinsic light-evoked spiking response of an M2 cell, recorded in cell-attached mode, was increased by $500 \mathrm{~nm}$ orexin-A. A light flash with an intensity of $9.61 \mathrm{log}$ photons $/ \mathrm{cm}^{2} / \mathrm{s}$ (3 s duration, $475 \mathrm{~nm}$ ) was used. $\boldsymbol{B}$, Bar chart shows that orexin-A significantly increased the average spiking rates of $M 2$ cells. $\boldsymbol{C}$, Extrinsic photocurrents of an M2 cell recorded in voltage-clamp mode in Ames' medium and in the presence of 500 nм orexin-A. $\boldsymbol{D}$, Bar chart shows that orexin-A had no effect on the photocurrents of M2 cells. $\boldsymbol{E}$, Extrinsic photocurrents of an $\mathrm{M} 2$ cell, recorded in Ames' medium and in the presence of $500 \mathrm{~nm}$ orexin-A in Opn4 ${ }^{-1-}$ retina. $F$, Bar chart shows that orexin-A did not change the photocurrents of M2 cells in Opn4 ${ }^{-1-}$ retinas. $V_{\text {hold }}=-73 \mathrm{mV}$. $* p<0.05$. $* * p<0.01$. n.S., not significant.

in Opn $4^{-/-}$retinas; and as expected, no significant effect of orexin-A on M2 cell extrinsic photocurrent was detected $[293.93 \pm 54.59 \mathrm{pA}$ (orexin-A) vs $307.83 \pm 53.36 \mathrm{pA}$ (control), $p>0.05, n=7]$ (Fig. 6E,F).

Orexin-A has no effect on intrinsic and extrinsic light responses of $\mathrm{M} 1$ cells

It has been reported that the M1 cell is a critical subtype of ipRGCs projecting to OPN and mediates the PLR (Baver et al., 2008). Figure $7 A$ shows an LY-filled M1 cell in the Opn4- $t d$ Tomato retina, which is characterized by relatively sparser dendritic branches exclusively stratifying in the OFF sublamina of the IPL. Perfusion of $500 \mathrm{~nm}$ orexin-A had no effect on the intrinsic light-evoked spiking rates in response to a $3 \mathrm{~s}$ light step $\left(475 \mathrm{~nm}, 10.9 \log\right.$ photons $\left./ \mathrm{cm}^{2} / \mathrm{s}\right)$ of $\mathrm{M} 1$ cells $[16.58 \pm 3.67 \mathrm{~Hz}$ (orexin-A) vs $19.13 \pm 5.46 \mathrm{~Hz}$ (control) for short period, $2.87 \pm 0.36 \mathrm{~Hz}$ (orexin-A) vs $3.12 \pm 0.48 \mathrm{~Hz}$ (control) for long period, $p>0.05$ in both cases, $n=6$ ] (Fig. $7 B-D$ ). Even when orexin-A concentration was increased to as high as $1000 \mathrm{~nm}$, the spiking rates were still not significantly changed for short period $[12.63 \pm 3.40 \mathrm{~Hz}$ (orexin-A) vs $12.75 \pm 3.00 \mathrm{~Hz}$ (control), $p>0.05, n=4$ ] (Fig. 7E). Similar results were obtained when the data collection period was extended to a 60 -s-long period (Fig. $7 F$ ). In addition, administration of the dual OXR antagonist TCS1102 $(10 \mu \mathrm{M})$ did not significantly affect the intrinsic lightevoked spiking rates of M1 cells [11.54 $\pm 1.06 \mathrm{~Hz}$ (TCS1102) vs $11.67 \pm 0.55 \mathrm{~Hz}$ (control) for short period, $3.41 \pm 0.65 \mathrm{~Hz}$ (TCS1102) vs $3.18 \pm 0.51 \mathrm{~Hz}$ (control) for long period, $p>0.05$ in both cases, $n=4$ ], confirming a lack of orexinergic modulation (Fig. 7G-I). Orexin-A (500 nM) also had no effect on the intrinsic photocurrent of $\mathrm{M} 1$ cells $[136.83 \pm 23.28 \mathrm{pA}$ (orexin-A) vs $136.51 \pm 24.16 \mathrm{pA}$ (control), $p>0.05, n=7$ ] (Fig. 7J,K). Furthermore, orexin-A (500 nM) failed to alter the resting membrane potential of M1 cells in Ames' medium [-54.24 $\pm 1.97 \mathrm{mV}$ (orexinA) vs $-55.14 \pm 1.68 \mathrm{mV}$ (control), $n=9, p>0.05$ ] (Fig. $7 L$ ) or in cocktail $[-63.95 \pm 0.95 \mathrm{mV}$ (orexin-A) vs $-64.36 \pm 0.71 \mathrm{mV}$ (control), $n=7, p>0.05$ ] (Fig. $7 M$ ). The extrinsic photocurrent of M1 cells, which was recorded in the Opn $4^{-1-}$ mouse retina, was also not altered (data not shown). Thus, M1 cells are seemingly not involved in the orexin-A-induced intensification of the mouse PLR.

\section{$\mathrm{OX}_{1} \mathrm{R}$ transcripts are differentially expressed in $\mathrm{M} 2$ and $\mathrm{M} 1$ ipRGCs}

A possible explanation for light responses of M2, but not M1 cells, being affected by orexin-A may be that $\mathrm{OX}_{1}$ Rs are differentially expressed in these two ipRGC subtypes. To address this issue, the expression levels of $\mathrm{OX}_{1} \mathrm{R}$ mRNA were compared between M2 and M1 cells by conducting RNAscope ISH for $\mathrm{OX}_{1} \mathrm{R}$ mRNA, together with immunostaining using antibodies against tdTomato and melanopsin.

First, we conducted a set of control experiments to evaluate background staining level and to ensure that the specimen for RNAscope analysis is appropriately prepared. Negative control probe to bacterial dihydrodipicolinate reductase (Dapb) revealed nearly complete absence of fluorescent punctuate staining in vertical sections prepared from Opn4-tdTomato retinas (Fig. 8A1), a result very similar to that obtained when the $\mathrm{OX}_{1} \mathrm{R}$ probe was omitted (Fig. 8A2), suggesting no nonspecific staining. In contrast, when polymerase II subunit A (polr2a), a rigorous positive control probe widely used for low copy tissues such as the retina, was used, punctuate labeling could be clearly seen, confirming the good preservation of sample RNA (Fig. 8A3).

In Opn4-tdTomato retinas, cell bodies with immunoenhanced tdTomato signals were targeted, and their cell-subtype identities were determined based on dendritic stratification patterns in the IPL revealed by a melanopsin antibody (UF-008), which clearly labels the entire dendritic fields of M2 and M1 cells. Whereas those with dendrites stratifying immediately adjacent to the somata and exclusively in the ON sublamina are M2 cells, those ramifying in the outermost part of the IPL are M1 cells (Berson et al., 2010). In a vast majority (14 of 15, 93.3\%) of M2 cells tested, $\mathrm{OX}_{1} \mathrm{R}$ transcript puncta were colocalized with the somata (Fig. 8B1-B4). In contrast, no $\mathrm{OX}_{1} \mathrm{R}$ transcript puncta 
were found in a majority (75.0\%) of 16 M1 cells examined (Fig. 8C1-C4). In remaining $4 \mathrm{M} 1$ cells, a trace amount of $\mathrm{OX}_{1} \mathrm{R}$ transcripts could be detected. Similar results were obtained in M1 cells of C57BL/6 mice for which RNAscope was used to label $\mathrm{OX}_{1} \mathrm{R}$ transcripts and another M1-preferred melanopsin antibody, PA1-780, was used for M1 cell labeling (X. S. Wu et al., 2019). In a comparable majority (13 of $17,76.5 \%$ ) of $\mathrm{M} 1$ cells examined, no $\mathrm{OX}_{1} \mathrm{R}$ transcript puncta were detected (Fig. 8D1-D3), and only a very limited number of puncta could be seen in the rest. When $\mathrm{OX}_{1} \mathrm{R}$ transcript puncta were counted and compared, it immediately became evident that M2 cells expressed much higher levels of $\mathrm{OX}_{1} \mathrm{R}$ mRNA $(2.07 \pm 0.36 /$ cell $)$ than M1 cells (UF-008-labeled M1s: $0.31 \pm 0.15 /$ cell; PA1-780-labeled M1s: $0.35 \pm 0.17 /$ cell; Dunn's multiple comparison test, $p<0.001$ in both cases; Fig. $8 E 1)$. Moreover, as a negative control, rotating the $\mathrm{OX}_{1} \mathrm{R}$ channel in the image by 180 degree eliminated the difference in puncta numbers among the three groups (UF-008-labeled M2s: $0.27 \pm$ 0.15/cell; UF-008-labeled M1s: $0.06 \pm$ 0.06/cell; PA1-780-labeled M1s: $0.12 \pm 0.08$ / cell; Kruskal-Wallis test, $p>0.05$; Fig. $8 E 2)$. Such differential expression of $\mathrm{OX}_{1} \mathrm{R}$ mRNA might, at least in part, account for the M2-specific modulation by orexin-A observed in this study.

\section{Discussion}

Orexin-A modulates both $\mathrm{rod} /$ coneand melanopsin-mediated pupillary constriction

Modulation by orexin of the activity of retinal neurons that are responsible for image-forming visual function has been demonstrated (Zheng et al., 2015; Qiao et al., 2017; G. Zhang et al., 2018). In the outer retina, orexin-B increases the activity of rod-driven bipolar cells in rat retina by suppressing GABAergic inhibitory feedback from ACs to these cells. Such modulation improves the visual acuity and contrast sensitivity of animals in dark periods (G. Zhang et al., 2018). In the inner retina, orexin-A suppresses AMPAR-mediated currents of GCs but enhances these currents in ACs via signaling pathways driven by the activation of $\mathrm{OX}_{1} \mathrm{Rs}$ and $\mathrm{OX}_{2} \mathrm{Rs}$, respectively (Zheng et al., 2015). Orexin-A also suppresses the light responses of dopaminergic ACs (Qiao et al., 2017). Whether and how orexins modulate non-image-forming visual function, however, are
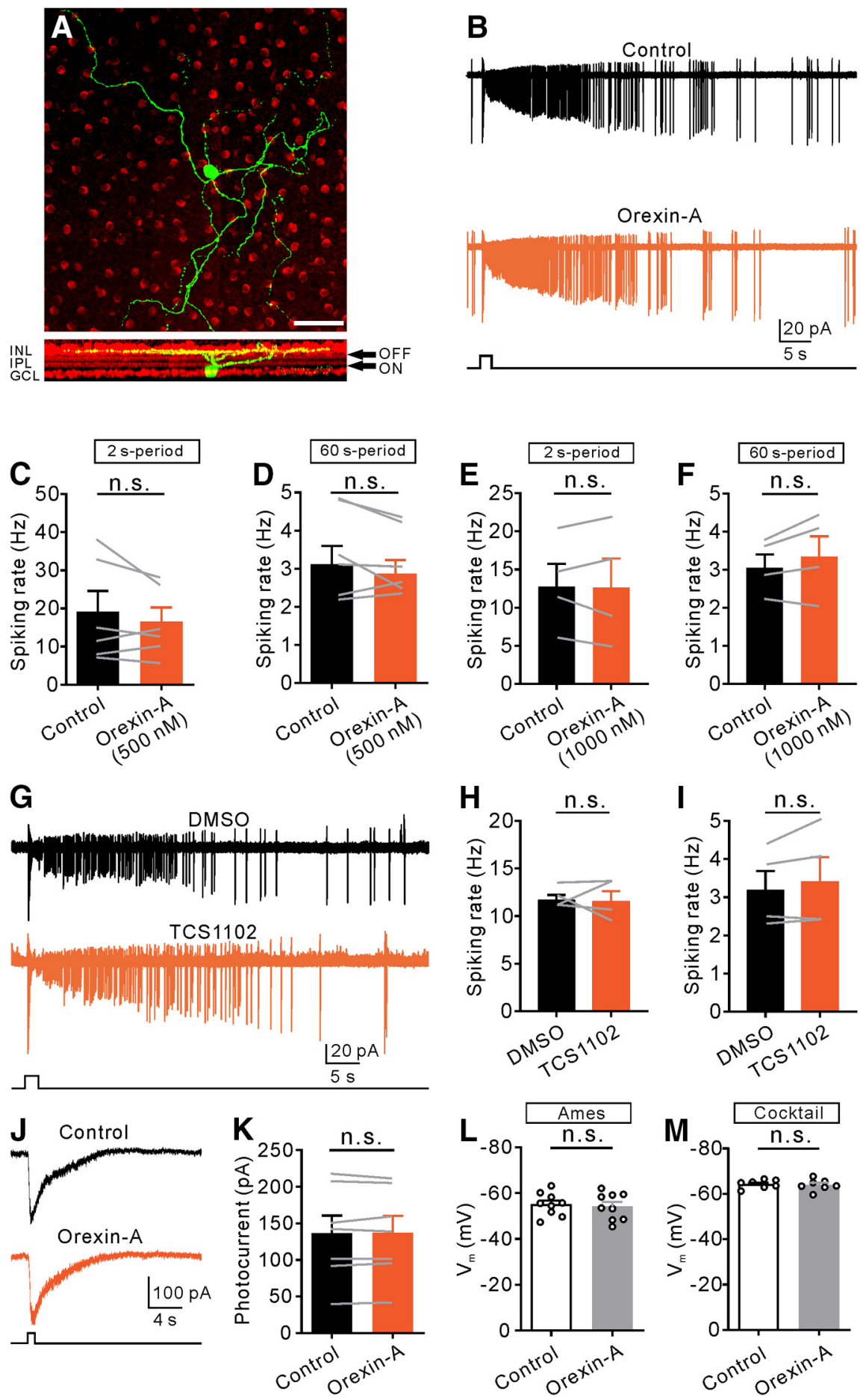

Figure 7. Orexin-A has no effect on intrinsic light responses of M1 cells. $A$, Confocal microphotographs of a whole-mount mouse retina, showing that an M1 cell filled with LY (green) is coimmunolabeled with ChAT (red). Scale bar, $40 \mu \mathrm{m}$. GCL, GC layer; INL, inner nuclear layer; ON, ON sublamina; OFF, OFF sublamina. B, Representative intrinsic light-evoked spiking responses of an $\mathrm{M} 1$ cell recorded in cell-attached mode, before and during application of 500 nM orexin-A. C, D, Bar charts show that orexin-A had no effect on the average spiking rates of $\mathrm{M} 1$ cells for short $(\boldsymbol{C})$ and long periods $(\boldsymbol{D})$ after light onset. $\boldsymbol{E}, \boldsymbol{F}$, Bar chart shows that intrinsic light-evoked spiking rates of $M 1$ cells recorded with addition of 1000 nM orexin-A, for short $(\boldsymbol{E})$ and long periods $(\boldsymbol{F})$ after light onset, were not much different from those recorded under control conditions. $\boldsymbol{G}$, Representative intrinsic light-evoked spiking responses of an M1 cell before and during application of $10 \mu \mathrm{M}$ TCS1102. $\boldsymbol{H}, \boldsymbol{I}$, Pooled data show that TCS1102 had no effect on the average spiking rates of M1 cells for short $(\boldsymbol{H})$ and long periods $(\boldsymbol{I})$ after light onset. $J$, Intrinsic photocurrents of an M1 cell recorded in voltage-clamp mode before and during application of orexinA. $V_{\text {hold }}=-73 \mathrm{mV}$. $\boldsymbol{K}$, Bar chart shows that orexin-A had no effect on intrinsic photocurrents of M1 cells. $\boldsymbol{L}$, The resting membrane potentials of $M 1$ cells in Ames' medium were measured in the absence and presence of $500 \mathrm{~nm}$ orexin-A. No significant difference could be found between the two datasets. $\boldsymbol{M}$, Orexin-A also did not alter the resting membrane potential of $M 1$ cells in the glutamatergic blocker cocktail. n.s., not significant. 

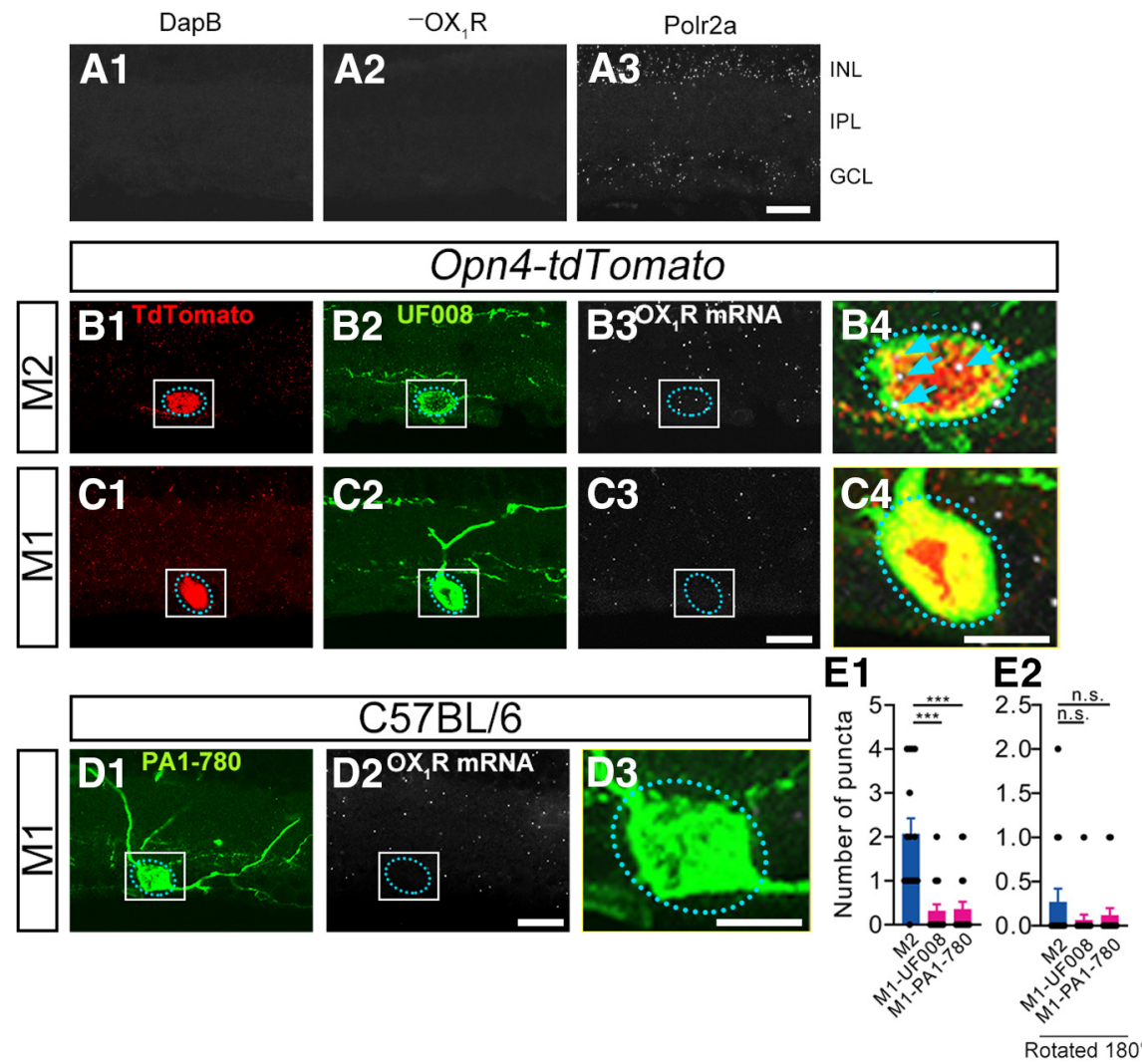

Figure 8. $\quad O X_{1} R$ transcript is differentially expressed on $M 2$ and $M 1$ cells, as revealed by RNAscope ISH in combination with immunostaining. A1-A3, Representative microphotographs showing that the negative control probe DapB detected no punctuate signals in an Opn4-tdTomato retinal section $(\boldsymbol{A 1})$, which was similar to the results obtained by omission of the $0 \mathrm{X}_{1} \mathrm{R}$ probe $(\boldsymbol{A} 2)$, whereas the positive control probe Polr2a detected abundant signals in the retinal sections harvested from the same animal. B1, B2, Microphotographs of an M2 cell in an Opn4-tdTomato retinal section, which was stained by antibodies recognizing tdTomato $(\boldsymbol{B} 1)$ and melanopsin (UF-008, $\boldsymbol{B 2}$ ). $\boldsymbol{B 3}, 0 \mathrm{X}_{1} \mathrm{R}$ transcripts in the section labeled by RNAscope technique. $B 4$, Merged and enlarged image of the boxed area in $\boldsymbol{A 1}-\mathbf{A} \mathbf{3}$, showing several $O \mathrm{X}_{1} \mathrm{R}$ transcript puncta in the soma of the $\mathrm{M} 2$ cell (arrows). C1-C4, Microphotographs of an M1 cell in another Opn4-tdTomato retinal section, which was processed with the same procedure as that shown in $\mathbf{B 1}-\mathbf{B 4}$. No OX $\mathrm{R}$ transcript puncta were seen in the soma. D1-D3, Microphotographs of an $\mathrm{M} 1$ cell collected from a $\mathrm{C} 57 \mathrm{BL} / 6$ retinal section, which was stained with a melanopsin antibody primarily probing $\mathrm{M} 1$ cells (PA1-780, D1), and then hybridized using RNAscope with the probe targeting OX $\mathrm{X}_{1} \mathrm{R}$ mRNA (D2). D3, Merged and enlarged image showing that $O X_{1} R$ mRNA signals were not seen in the cell. E1, E2, Bar charts showing that significantly more $O X_{1} R$ mRNA puncta were localized to $M 2$ cell somata than to $M 1$ somata (E1), but such a difference was canceled when the $0 X_{1} R$ channel was rotated by 180 degrees (E2), arguing against a "by chance" localization of puncta in M2s. $* * * p<0.001$. Scale bars: A3, C3, D2, $20 \mu \mathrm{m} ; \mathbf{C 4}, \mathbf{D 3}, 10 \mu \mathrm{m}$. n.S., not significant.

unknown. In the present study, we first showed that the effect of orexin-A and TCS1102 on pupil size was of opposite signs. Furthermore, in $r d / r d ~ c l$ and Opn $4^{-1-}$ mice, the $\mathrm{rod} /$ cone-driven and melanopsin-driven components of PLRs were similarly modulated by orexin-A. These results demonstrate for the first time that orexin modulates the PLR, an important component of non-image-forming vision, by intensifying pupillary constriction.

\section{Mechanisms underlying the orexin-induced increase in excitability of M2 cells}

There are several reasons to believe that the orexin-A-induced effect could be because of the effect of orexin-A on light-evoked spiking rates of ipRGCs. First, PLR is controlled by the OPN (Clarke and Ikeda, 1985) to which M1 and M2 cells primarily project (Baver et al., 2008). Second, there is evidence showing that brighter light causes increased activity of M2 ipRGCs (Zhao et al., 2014). Such an increment is known to enhance pupillary constriction (Keenan et al., 2016; Milosavljevic et al., 2018), which is minimal when light-induced GC spiking is blocked by TTX (Webb et al., 2013). Third, both the effects of TCS1102 on pupillary constriction in mice and on light-evoked spiking rates of M2 cells were changed in a stimulus intensitydependent manner, and the effects of TCS1102 on both were similar.

As in other regions of the brain (Kim et al., 2009; Mukai et al., 2009; J. Zhang et al., 2011), the increase in pupillary constriction induced by orexin-A may be attributed to an increase in the intrinsic membrane excitability of M2 cells because of the membrane depolarization. This effect of orexin seems ubiquitous and could explain why orexin excited almost all target neurons in the brain (Kukkonen et al., 2002; Sakurai, 2007), except for glucose-responsive neurons in the ventromedial hypothalamic nucleus, in which the activity was reduced by orexin (Shiraishi et al., 2000). This likely represents a direct effect on postsynaptic activity, as observed in other central neurons, because the membrane depolarization was barely affected when chemical synaptic transmission was blocked and gap junctions were uncoupled.

In different central neurons, orexinA-induced excitatory effects may be mediated by $\mathrm{OX}_{1}$ Rs (Kim et al., 2009; Ho et al., 2011; Dustrude et al., 2018), $\mathrm{OX}_{2} \mathrm{Rs}$ (Mukai et al., 2009; Yu et al., 2010), or both subtypes of OXRs (J. Zhang et al., 2011). We have shown that the increase in intrinsic light-evoked spiking rate of M2 cells by orexin-A could be reversed by the specific $\mathrm{OX}_{1} \mathrm{R}$ antagonist SB334867, but not by the specific $\mathrm{OX}_{2} \mathrm{R}$ antagonist TCS OX229, strongly suggesting the involvement of $\mathrm{OX}_{1}$ Rs. Indeed, the expression of $\mathrm{OX}_{1} \mathrm{R}$ on $\mathrm{M} 2$ cells was demonstrated by RNAscope ISH for $\mathrm{OX}_{1} \mathrm{R}$ mRNA. As shown in Figure $8 B, E$, in a vast majority (93.3\%) of M2 cells, $\mathrm{OX}_{1} \mathrm{R}$ transcript puncta were localized in the somata of these cells. Notably, the application of orexin-A did not affect M1 cells, indicating that these cells are not involved in the orexin-induced modulation of the PLR, although $\sim 45 \%$ of the fibers projecting to OPN originate in M1 cells (Baver et al., 2008). Consistently, no $\mathrm{OX}_{1} \mathrm{R}$ transcript puncta were found in a majority of $\mathrm{M} 1$ cells (Fig. $8 C-E$ ). It should be noted that a trace amount of $\mathrm{OX}_{1} \mathrm{R}$ transcripts could be detected in a small fraction of M1 cells. Further study should be conducted to explore whether these transcripts may be eventually translated into $\mathrm{OX}_{1} \mathrm{R}$ proteins.

Similar to most of the central neurons examined to date, the increased firing rate of M2 cells induced by orexin-A was mainly because of membrane depolarization. The ionic mechanisms underlying the depolarization are closely related to the signal transduction pathways induced by activation of $\mathrm{OX}_{1} \mathrm{Rs}$. They may be complex and cell type-dependent. A variety of processes could be involved, including inhibition of $\mathrm{K}^{+}$channels, activation of NSCCs, and activation of voltage-gated $\mathrm{Ca}^{2+}$ channels, etc (Eriksson et al., 2001; Yang and Ferguson, 2002; J. Zhang et 
al., 2011). In this study, the ionic basis was first explored by examining the effects of orexin-A on $I-V$ relations of M2 cells. It was found that more than one type of orexin-A-induced change in $I$ - $V$ curves was seen. Such a result was reminiscent of those reported in previous studies, in which the effects of orexin on lateral vestibular nucleus neurons (J. Zhang et al., 2011) and septohippocampal cholinergic neurons (M. Wu et al., 2004) were investigated, thus suggesting the contribution of multiple ion channels. In the pharmacological experiments conducted subsequently, suppression of orexin-A-induced depolarization by $\mathrm{Ba}^{2+}$ suggests the involvement of $\mathrm{K}^{+}$channels. The involvement of Kir channels is further suggested by the reduced depolarization caused by the Kir channel blocker Tertiapin-Q. During depolarization, Kir channels, which control the resting membrane potential, are closed (Nishida and MacKinnon, 2002). Therefore, orexin-A seems to increase the firing rates of M2 cells by closing Kir channels, as evidenced by the increased input resistance. $\mathrm{K}^{+}$channel involvement in the effects of orexin-A is commonly seen in central neurons (Kim et al., 2009; J. Zhang et al., 2011). However, the channels that function together with $\mathrm{K}^{+}$channels in central neurons could be cell type-dependent. In lateral vestibular nuclear neurons, for example, activation of $\mathrm{Na}^{+}-\mathrm{Ca}^{2+}$ exchangers along with closure of Kir channels mediate orexin-A-induced depolarization; but in the neurons of the nucleus accumbens shell, the orexin-A-induced depolarization is generated by activating NSCCs and suppressing $\mathrm{K}^{+}$channels (Mukai et al., 2009; J. Zhang et al., 2011). NSCCs are voltage-independent channels that allow the passage of cations of different proportions (Kramer and Zucker, 1985), and they are involved in regulating the excitability of neurons in various systems (Bourque, 1989; Hiruma and Bourque, 1995; Yang and Ferguson, 2002). In this study, orexin-A was found to modify NSCCs, which induced cation influx, thereby depolarizing M2 cells.

\section{Functional implications of orexin-induced pupillary constriction}

It is generally thought that orexins are synthesized exclusively in neurons in the hypothalamus (Peyron et al., 1998; Nambu et al., 1999). Orexin activity in other regions may be because of orexinergic neurons extensively projecting to almost the whole brain (Peyron et al., 1998). However, orexins in the retina were unlikely to have been transported from the hypothalamus, and immunohistochemical assay demonstrated the presence of orexins in rat retinal neurons. Notably, orexin-A and -B were detected in ipRGCs, suggesting that the $\mathrm{OX}_{1} \mathrm{R}$ expressed in ipRGCs may function as an autoreceptor. Irrespective of whether orexins are produced in the retina and/or the hypothalamus, a critical question is how retinal orexin release is regulated by light. We speculate that orexin release in darkness is reduced by light for the following reasons. First, in the retina, neurotransmitters are released during darkness. There is evidence suggesting that neuropeptides, such as VIP and substance P, are coreleased with certain transmitters. Second, in the rat, a nocturnal animal, the orexin-A level in the lateral hypothalamus shows a robust diurnal change, being higher during wakefulness (dark period) and lower during the sleep phase (light period) (Estabrooke et al., 2001). Therefore, the retinal orexin level might also show a similar diurnal fluctuation. Third, an effect of the dual receptor antagonist TCS1102 on PLR was clearly seen in dark-adapted mouse eyes, suggesting a higher retinal orexin level in the dark. Orexins are known to promote wakefulness (Inutsuka and Yamanaka, 2013). Our results demonstrate that orexin increases pupillary constriction, which might improve the visual performance of awake mice. This is simply because, for a given optical system, a smaller aperture yields a greater focal depth.

While orexins in the brain are generally thought to be involved in regulating arousal/wakefulness (Inutsuka and Yamanaka, 2013) and higher-level functions, such as mood (Johnson et al., 2012), the present work shows that orexins also modulate pupillary constriction via a local ipRGCmediated retinal circuit. Interestingly, ipRGCs are also known to regulate sleep/arousal via their direct projections to the ventrolateral preoptic nucleus (Hattar et al., 2006; Rupp et al., 2019) and to modulate affective responses via communication between the retina and habenular nucleus (Lazzerini Ospri et al., 2017; Fernandez et al., 2018; Huang et al., 2019). It seems likely that orexinergic modulation of these sophisticated behavioral responses occurs not only in the brain but also via a local, intraretinal pathway. ipRGCselective modulation of OXRs is needed to evaluate this hypothesis.

\section{References}

Aranda ML, Schmidt TM (2020) Diversity of intrinsically photosensitive retinal ganglion cells: circuits and functions. Cell Mol Life Sci. Advance online publication. Retrieved September 23, 2020. doi: 10.1007/s00018020-03641-5.

Baver SB, Pickard GE, Sollars PJ, Pickard GE (2008) Two types of melanopsin retinal ganglion cell differentially innervate the hypothalamic suprachiasmatic nucleus and the olivary pretectal nucleus. Eur J Neurosci 27:17631770 .

Berson DM, Dunn FA, Takao M (2002) Phototransduction by retinal ganglion cells that set the circadian clock. Science 295:1070-1073.

Berson DM, Castrucci AM, Provencio I (2010) Morphology and mosaics of melanopsin-expressing retinal ganglion cell types in mice. J Comp Neurol 518:2405-2422

Bourque CW (1989) Ionic basis for the intrinsic activation of rat supraoptic neurones by hyperosmotic stimuli. J Physiol 417:263-277.

Caval-Holme F, Zhang Y, Feller MB (2019) Gap junction coupling shapes the encoding of light in the developing retina. Curr Biol 29:4024-4035.e4025.

Clarke RJ, Ikeda H (1985) Luminance and darkness detectors in the olivary and posterior pretectal nuclei and their relationship to the pupillary light reflex in the rat: 1 . Studies with steady luminance levels. Exp Brain Res 57:224-232.

Dacey DM, Liao HW, Peterson BB, Robinson FR, Smith VC, Pokorny J, Yau KW, Gamlin PD (2005) Melanopsin-expressing ganglion cells in primate retina signal colour and irradiance and project to the LGN. Nature 433:749-754.

de Lecea L, Sutcliffe JG (2005) The hypocretins and sleep. FEBS J 272:56755688.

de Lecea L, Kilduff TS, Peyron C, Gao X, Foye PE, Danielson PE, Fukuhara C, Battenberg EL, Gautvik VT, Bartlett FS, Frankel WN, van den Pol AN, Bloom FE, Gautvik KM, Sutcliffe JG (1998) The hypocretins: hypothalamus-specific peptides with neuroexcitatory activity. Proc Natl Acad Sci USA 95:322-327.

Do MT, Kang SH, Xue T, Zhong H, Liao HW, Bergles DE, Yau KW (2009) Photon capture and signalling by melanopsin retinal ganglion cells. Nature 457:281-287.

Do MT (2019) Melanopsin and the intrinsically photosensitive retinal ganglion cells: biophysics to behavior. Neuron 104:205-226.

Dustrude ET, Caliman IF, Bernabe CS, Fitz SD, Grafe LA, Bhatnagar S, Bonaventure P, Johnson PL, Molosh AI, Shekhar A (2018) Orexin depolarizes central amygdala neurons via orexin receptor 1 , phospholipase C and sodium-calcium exchanger and modulates conditioned fear. Front Neurosci 12:934. 
Emanuel AJ, Kapur K, Do MT (2017) Biophysical variation within the M1 type of ganglion cell photoreceptor. Cell Rep 21:1048-1062.

Eriksson KS, Sergeeva O, Brown RE, Haas HL (2001) Orexin/hypocretin excites the histaminergic neurons of the tuberomammillary nucleus. J Neurosci 21:9273-9279.

Estabrooke IV, McCarthy MT, Ko E, Chou TC, Chemelli RM, Yanagisawa M, Saper CB, Scammell TE (2001) Fos expression in orexin neurons varies with behavioral state. J Neurosci 21:1656-1662.

Fernandez DC, Fogerson PM, Lazzerini Ospri L, Thomsen MB, Layne RM, Severin D, Zhan J, Singer JH, Kirkwood A, Zhao H, Berson DM, Hattar S (2018) Light affects mood and learning through distinct retina-brain pathways. Cell 175:71-84.e18.

Guler AD, Ecker JL, Lall GS, Haq S, Altimus CM, Liao HW, Barnard AR, Cahill H, Badea TC, Zhao H, Hankins MW, Berson DM, Lucas RJ, Yau KW, Hattar S (2008) Melanopsin cells are the principal conduits for rod-cone input to non-image-forming vision. Nature 453:102105.

Hatori M, Le H, Vollmers C, Keding SR, Tanaka N, Buch T, Waisman A, Schmedt C, Jegla T, Panda S (2008) Inducible ablation of melanopsinexpressing retinal ganglion cells reveals their central role in non-imageforming visual responses. PLoS One 3:e2451.

Hattar S, Liao HW, Takao M, Berson DM, Yau KW (2002) Melanopsin-containing retinal ganglion cells: architecture, projections, and intrinsic photosensitivity. Science 295:1065-1070.

Hattar S, Lucas RJ, Mrosovsky N, Thompson S, Douglas RH, Hankins MW, Lem J, Biel M, Hofmann F, Foster RG, Yau KW (2003) Melanopsin and rod-cone photoreceptive systems account for all major accessory visual functions in mice. Nature 424:76-81.

Hattar S, Kumar M, Park A, Tong P, Tung J, Yau KW, Berson DM (2006) Central projections of melanopsin-expressing retinal ganglion cells in the mouse. J Comp Neurol 497:326-349.

Hiruma H, Bourque CW (1995) P2 purinoceptor-mediated depolarization of rat supraoptic neurosecretory cells in vitro. J Physiol 489:805-811.

Ho YC, Lee HJ, Tung LW, Liao YY, Fu SY, Teng SF, Liao HT, Mackie K, Chiou LC (2011) Activation of orexin 1 receptors in the periaqueductal gray of male rats leads to antinociception via retrograde endocannabinoid (2-arachidonoylglycerol)-induced disinhibition. J Neurosci 31:1460014610

Huang L, Xi Y, Peng Y, Yang Y, Huang X, Fu Y, Tao Q, Xiao J, Yuan T, An K, Zhao H, Pu M, Xu F, Xue T, Luo M, So KF, Ren C (2019) A visual circuit related to habenula underlies the antidepressive effects of light therapy. Neuron 102:128-142.e128

Inutsuka A, Yamanaka A (2013) The physiological role of orexin/hypocretin neurons in the regulation of sleep/wakefulness and neuroendocrine functions. Front Endocrinol (Lausanne) 4:18.

Johnson PL, Molosh A, Fitz SD, Truitt WA, Shekhar A (2012) Orexin, stress, and anxiety/panic states. Prog Brain Res 198:133-161.

Keenan WT, Rupp AC, Ross RA, Somasundaram P, Hiriyanna S, Wu Z, Badea TC, Robinson PR, Lowell BB, Hattar SS (2016) A visual circuit uses complementary mechanisms to support transient and sustained pupil constriction. eLife 5:e15392.

Kim J, Nakajima K, Oomura Y, Wayner MJ, Sasaki K (2009) Electrophysiological effects of orexins/hypocretins on pedunculopontine tegmental neurons in rats: an in vitro study. Peptides 30:191-209.

Kowalski J, Gan J, Jonas P, Pernia-Andrade AJ (2016) Intrinsic membrane properties determine hippocampal differential firing pattern in vivo in anesthetized rats. Hippocampus 26:668-682.

Kramer RH, Zucker RS (1985) Calcium-dependent inward current in Aplysia bursting pace-maker neurones. J Physiol 362:107-130.

Kukkonen JP, Holmqvist T, Ammoun S, Akerman KE (2002) Functions of the orexinergic/hypocretinergic system. Am J Physiol Cell Physiol 283: C1567-C1591.

Lazzerini Ospri L, Prusky G, Hattar S (2017) Mood, the circadian system, and melanopsin retinal ganglion cells. Annu Rev Neurosci 40:539-556.

Liu F, Xu GZ, Wang L, Jiang SX, Yang XL, Zhong YM (2011) Gene expression and protein distribution of orexins and orexin receptors in rat retina. Neuroscience 189:146-155.

Lucas RJ, Freedman MS, Muñoz M, Garcia-Fernández JM, Foster RG (1999) Regulation of the mammalian pineal by non-rod, non-cone, ocular photoreceptors. Science 284:505-507.
Matsuki T, Sakurai T (2008) Orexins and orexin receptors: from molecules to integrative physiology. Results Probl Cell Differ 46:27-55.

Milosavljevic N, Storchi R, Eleftheriou CG, Colins A, Petersen RS, Lucas RJ (2018) Photoreceptive retinal ganglion cells control the information rate of the optic nerve. Proc Natl Acad Sci USA 115:E11817E11826.

Mukai K, Kim J, Nakajima K, Oomura Y, Wayner MJ, Sasaki K (2009) Electrophysiological effects of orexin/hypocretin on nucleus accumbens shell neurons in rats: an in vitro study. Peptides 30:1487-1496

Mukherjee S, Ayaub EA, Murphy J, Lu C, Kolb M, Ask K, Janssen LJ (2015) Disruption of calcium signaling in fibroblasts and attenuation of bleomycin-induced fibrosis by nifedipine. Am J Respir Cell Mol Biol 53:450458.

Nambu T, Sakurai T, Mizukami K, Hosoya Y, Yanagisawa M, Goto K (1999) Distribution of orexin neurons in the adult rat brain. Brain Res 827:243260

Nelson AB, Krispel CM, Sekirnjak C, du Lac S (2003) Long-lasting increases in intrinsic excitability triggered by inhibition. Neuron 40:609-620.

Nishida M, MacKinnon R (2002) Structural basis of inward rectification: cytoplasmic pore of the $\mathrm{G}$ protein-gated inward rectifier GIRK1 at $1.8 \mathrm{~A}$ resolution. Cell 111:957-965.

Peyron C, Tighe DK, van den Pol AN, de Lecea L, Heller HC, Sutcliffe JG, Kilduff TS (1998) Neurons containing hypocretin (orexin) project to multiple neuronal systems. J Neurosci 18:9996-10015.

Qiao SN, Zhou W, Liu LL, Zhang DQ, Zhong YM (2017) Orexin-A suppresses signal transmission to dopaminergic amacrine cells from outer and inner retinal photoreceptors. Invest Ophthalmol Vis Sci 58:47124721.

Quattrochi LE, Stabio ME, Kim I, Ilardi MC, Fogerson PM, Leyrer ML, Berson DM (2019) The M6 cell: a small-field bistratified photosensitive retinal ganglion cell. J Comp Neurol 527:297-311.

Remtulla S, Hallett PE (1985) A schematic eye for the mouse, and comparisons with the rat. Vision Res 25:21-31.

Rupp AC, Ren M, Altimus CM, Fernandez DC, Richardson M, Turek F, Hattar S, Schmidt TM (2019) Distinct ipRGC subpopulations mediate light's acute and circadian effects on body temperature and sleep. eLife 8: e44358.

Sakurai T (2007) The neural circuit of orexin (hypocretin): maintaining sleep and wakefulness. Nat Rev Neurosci 8:171-181.

Sakurai T, Amemiya A, Ishii M, Matsuzaki I, Chemelli RM, Tanaka H, Williams SC, Richardson JA, Kozlowski GP, Wilson S, Arch JR, Buckingham RE, Haynes AC, Carr SA, Annan RS, McNulty DE, Liu WS, Terrett JA, Elshourbagy NA, Bergsma DJ, et al. (1998) Orexins and orexin receptors: a family of hypothalamic neuropeptides and $G$ protein-coupled receptors that regulate feeding behavior. Cell 92: 573-585.

Sakurai T, Mieda M, Tsujino N (2010) The orexin system: roles in sleep/wake regulation. Ann NY Acad Sci 1200:149-161.

Schmidt TM, Kofuji P (2009) Functional and morphological differences among intrinsically photosensitive retinal ganglion cells. J Neurosci 29:476-482.

Schmidt TM, Kofuji P (2010) Differential cone pathway influence on intrinsically photosensitive retinal ganglion cell subtypes. J Neurosci 30:1626216271

Schmidt TM, Kofuji P (2011) Structure and function of bistratified intrinsically photosensitive retinal ganglion cells in the mouse. J Comp Neurol 519:1492-1504

Schmidt TM, Alam NM, Chen S, Kofuji P, Li W, Prusky GT, Hattar S (2014) A role for melanopsin in alpha retinal ganglion cells and contrast detection. Neuron 82:781-788.

Shiraishi T, Oomura Y, Sasaki K, Wayner MJ (2000) Effects of leptin and orexin-A on food intake and feeding related hypothalamic neurons. Physiol Behav 71:251-261.

Sondereker KB, Stabio ME, Renna JM (2020) Crosstalk: the diversity of melanopsin ganglion cell types has begun to challenge the canonical divide between image-forming and non-image-forming vision. J Comp Neurol 528:2044-2067.

Sonoda T, Lee SK, Birnbaumer L, Schmidt TM (2018) Melanopsin phototransduction is repurposed by ipRGC subtypes to shape the function of distinct visual circuits. Neuron 99:754-767.e754. 
Stabio ME, Sabbah S, Quattrochi LE, Ilardi MC, Fogerson PM, Leyrer ML, Kim MT, Kim I, Schiel M, Renna JM, Briggman KL, Berson DM (2018) The M5 cell: a color-opponent intrinsically photosensitive retinal ganglion cell. Neuron 97:150-163.e154.

Webb IC, Coolen LM, Lehman MN (2013) NMDA and PACAP receptor signaling interact to mediate retinal-induced SCN cellular rhythmicity in the absence of light. PLoS One 8:e76365.

Wu M, Zaborszky L, Hajszan T, van den Pol AN, Alreja M (2004) Hypocretin/orexin innervation and excitation of identified septohippocampal cholinergic neurons. J Neurosci 24:35273536.

Wu XS, Wang YC, Liu TT, Wang L, Sun XH, Wang LQ, Weng SJ, Zhong YM (2019) Morphological alterations of intrinsically photosensitive retinal ganglion cells after ablation of mouse photoreceptors with selective photocoagulation. Exp Eye Res 188:107812.

Xue T, Do MT, Riccio A, Jiang Z, Hsieh J, Wang HC, Merbs SL, Welsbie DS, Yoshioka T, Weissgerber P, Stolz S, Flockerzi V, Freichel M, Simon MI, Clapham DE, Yau KW (2011) Melanopsin signalling in mammalian iris and retina. Nature 479:67-73.
Yang B, Ferguson AV (2002) Orexin-A depolarizes dissociated rat area postrema neurons through activation of a nonselective cationic conductance. J Neurosci 22:6303-6308.

Yu L, Zhang XY, Zhang J, Zhu JN, Wang JJ (2010) Orexins excite neurons of the rat cerebellar nucleus interpositus via orexin 2 receptors in vitro. Cerebellum 9:88-95.

Zhang G, Wu XH, Xu GZ, Weng SJ, Yang XL, Zhong YM (2018) Orexin-B modulates synaptic transmission of rod bipolar cells in rat retina. Neuropharmacology 133:38-50.

Zhang J, Li B, Yu L, He YC, Li HZ, Zhu JN, Wang JJ (2011) A role for orexin in central vestibular motor control. Neuron 69:793-804.

Zhao X, Stafford BK, Godin AL, King WM, Wong KY (2014) Photoresponse diversity among the five types of intrinsically photosensitive retinal ganglion cells. J Physiol 592:1619-1636.

Zheng C, Deng QQ, Liu LL, Wang MY, Zhang G, Sheng WL, Weng SJ, Yang XL, Zhong YM (2015) Orexin-A differentially modulates AMPA-preferring responses of ganglion cells and amacrine cells in rat retina. Neuropharmacology 93:80-93. 